NBER WORKING PAPER SERIES

\author{
CIGARETTE TAXATION AND THE \\ SOCIAL CONSEQUENCES OF SMOKING
}

W. Kip Viscusi

Working Paper No. 4891

\author{
NATIONAL BUREAU OF ECONOMIC RESEARCH \\ 1050 Massachusetts Avenue \\ Cambridge, MA 02138 \\ October 1994
}

Paper prepared for 1994 National Bureau of Economic Research Conference on Tax Policy and the Economy, Washington, D.C., November 1, 1994. Robert Scharff provided superb research assistance. The editor and members of the Duke Public Finance Workshop provided helpful comments. This paper is part of NBER's research programs in Health Economics and Public Economics. Any opinions expressed are those of the author and not those of the National Bureau of Economic Research.

(c) 1994 by W. Kip Viscusi. All rights reserved. Short sections of text, not to exceed two paragraphs, may be quoted without explicit permission provided that full credit, including (c) notice, is given to the source. 


\title{
CIGARETTE TAXATION AND THE SOCIAL CONSEQUENCES OF SMOKING
}

\begin{abstract}
This paper assesses the appropriate cigarette tax needed to address potential market failures. There is no evidence of inadequate risk decisions by smokers regarding their own welfare. Detailed calculations of the financial externalities of smoking indicate that the financial savings from premature mortality in terms of lower nursing home costs and retirement pensions exceed the higher medical care and life insurance costs generated. The costs of environmental tobacco smoke are highly uncertain, but of potentially substantial magnitude. Even with recognition of these costs, current cigarette taxes exceed the magnitude of the estimated net externalities.
\end{abstract}

W. Kip Viscusi

Department of Economics

Duke University

Box 90097

Durham, NC 27708-0097 


\section{Introduction}

Cigarette smoking has long been the object of social controversy and policy interventions. However, in recent years this scrutiny has become increasingly great. Within 1994 alone there was an unusually large flurry of anti-smoking activity. The chairman of the Food and Drug Administration speculated that cigarettes should be regulated by that agency because, in his view, nicotine is addictive. The occupational safety and Health Administration proposed a ban on smoking in the workplace, except in situations in which firms provide designated, ventilated smoking areas.: similarly, congress, with the support of the U.S. Environmental Protection Agency, began considering legislation that would lead to a ban on public smoking. ${ }^{2}$

within the context of this anti-smoking fervor, legislators have also turned to cigarette taxes as a mechanism for raising revenues to partially finance the proposed health care reforms. Although Federal cigarette taxes are currently 24 cents per pack, the proposed legislation would increase these taxes further. The mid-1994 version of the clinton plan would impose a tax of 99 cents per pack, the health care proposal by senate majority leader George Mitchell would impose a tax of 69 cents per pack, and one draft health care bill from the House Education and Labor committee would impose a tax of two dollars per pack.

The legislators who proposed these taxes may overestimate the ultimate tax revenues if they fail to recognize the demand

1 See Federal Register (1994).

2 see the U.S. Environmental Protection Agency (1994). 
response. Not only is the demand for smoking quite elastic and similar to that of many other goods, but the long-run elasticity is even greater than in the short-run. As a result, economists such as Becker, Grossman, and Murphy (1994) have estimated that the long-run revenue effects of the cigarette taxes will ke less dramatic than the short-run revenue gains.

There are many reasons why from a political standpoint taxes might be imposed. One possible explanation is political expediency. Cigarette smokers now constitute a minority of the population. Moreover, given the social controversy pertaining to smoking, they are a vulnerable minority for which there will be lower political costs associated with taxation than, for example, a more broadly based tax.

There may also be legitimate economic rationales for taxing cigarettes, wholly apart from the desire to raise revenues. cigarette taxes and alcohol taxes are among the most widely used forms of "sin taxes." The economic rationale for such taxes is that imposing taxes discourages behavior that may be associated with inefficient decisions. The inadequacies in behavior may pertain to the choices by smokers with respect to their own wellbeing or that of their families. Taxes could be imposed to align these decisions with what would prevail if individual choices were rational from a self-interest standpoint. A second impetus for taxation would arise if there were net external costs imposed on the rest of society by cigarette smoking. In that case, cigarette taxes would function much like a Pigouvian tax to lead 
smokers to internalize the external costs of their actions.

Although the potential rationales for cigarette taxation are clear, whether or not there should be taxation of any $k$ ind from the standpoint of promoting efficient decisions is not theoretically obvious. Smokers may ignore the externality to their future selves and their families and make inadequate selfprotective decisions. However, there may also be distortions of the opposite type in which smokers overestimate the risk and place too great a weight on the losses involved. The efficient risk is not necessarily zero but rather one that reflects the competing benefits and costs associated with smoking activity. The externality aspects of smoking likewise involve competing effects. Cigarette smokers have no private incentive to internalize all of the effects of smoking on others, but these effects are not necessarily adverse on balance. To the extent that cigarette smoking leads to adverse health consequences, there will be higher health insurance costs associated with these illnesses as well as other social externalities, such as life insurance costs. However, there may also be offsetting cost savings from earlier mortality through reduced costs of pensions, Social Security, Medicare, and health expenditures later in life. In tallying these externalities, one should also take into account any adverse health effects of environmental tobacco smoke to the extent that these can be reliably estimated. It is not clear a priori whether the cost savings to society are exceeded by the costs imposed on society. Resolving these issues requires 
a detailed empirical assessment of the competing influences.

In this paper I will provide a careful examination of the social consequences of smoking both for the smoker and society at large. Past analyses directed at ascertaining the net cost of smoking and the appropriate taxation of smoking have focused only on one of the two components, either the individual effects or the societal insurance effects. This paper will be the first to incorporate both dimensions into the analysis. In addition, the assessment of the social consequences of smoking will include extensions that have not appeared in previous assessments. This analysis incorporates recognition of the possible costs associated with environmental tobacco smoke. In addition, all the risk assessments will recognize the changing character of cigarettes and, in particular, the dramatic reduction in the tar levels of cigarettes over the past several decades. In contrast, past risk assessments and evaluations of cigarettes have all utilized risk estimates that pertain to an era of cigarette smoking in which the product had quite different characteristics than those marketed today.

After reviewing the rationale for setting cigarette taxes in section 2, I will provide a profile of current cigarette taxes in Section 3. Cigarette tax revenues are quite substantial, but these taxes are also regressive in character, which is an unattractive feature. Section 4 details the shift in the tar characteristics in cigarettes and the implications of this shift for cigarette risk assessments. In section 5, I assess the 
externalities of cigarette smoking to the smoker's future self and to the smoker's family. Section 6 assesses the insurancerelated externalities associated with smoking, including effects on health insurance, social security, pensions, life insurance, and related programs. Section 7 broadens the discussion to include the public health risk consequences of environmental tobacco smoke. As the concluding section 8 indicates, on balance the net social consequences of smoking do not appear to be adverse. From the standpoint of an optimal sin tax, no additional taxation appears warranted. The current level of taxes already exceeds what is required to reflect the estimated adverse social consequences of smoking.

\section{Setting the Efficient Tax Level}

To determine the optimal sin tax in the case of cigarette smoking, one should assess how this tax should be adjusted to reflect both the potential welfare losses to smokers as well as the losses to society that are not accounted for in private smoking decisions. For the purpose of this discussion, I will hypothesize that individuals potentially underestimate the risks of smoking and that there are net societal costs imposed by smoking. If there are such market failures, how then could the tax system serve a constructive role in rectifying these errors in decisions? Frameworks such as these follow a logic that is natural for economists, but policymakers considering smoking taxes seldom frame these taxes in terms of deterring smoking in an efficient manner. In effect, the potential efficiency 
properties of the risky decisions are neglected, and there is typically exclusive emphasis on the potential errors in these decisions.

The framework here will focus on an individual decision maker. If this person does not smoke cigarettes, then the consumer will derive a welfare level $W(Y)$ from an income level $Y$. The consumer has the opportunity to purchase cigarettes at a price $P$, and doing so will lead to two possible health state outcomes, good health in which the individual derives a utility $U(Y-P)$ and ill health in which the utility level is $V(Y-P)$. The ill health state potentially could be death, in which case $V$ will serve as the bequest function. Assume that there is a true health risk $\pi$ posed by cigarettes, where this probability is not necessarily known to the decision maker. There is also a social loss $L$ that does not enter the decision maker's calculus of attractiveness of smoking, where the probability that the loss will be inflicted is $\pi$.

From the standpoint of social desirability of smoking, the individual is making a rational choice if the expected utility derived by the smoker from smoking exceeds the expected cost imposed on society plus the utility derived from not smoking, or

$$
(1-\pi) U(Y-P)+\pi V(Y-P)>W(Y)+\pi L .
$$

This formulation ignores the role of taxation, which will be introduced subsequently as a mechanism for eliminating potential errors in decisions.

There are two principal ways in which decisions might be 
flawed. First, individuals may not have accurate perceptions of the risk $\pi$, and second they will have no private incentive to recognize the net externality costs imposed by others. In particular, the private decision in the case in which there is not taxation will be based on the individual's assessed probability of ill health $q$, which may differ from $\pi$, leading to a private choice criterion of

$$
(1-q) U(Y-P)+q V(Y-P)>W(Y) \text {. }
$$

The private decision differs from the optimal social decision in that it neglects the expected externality cost and does not account for the possible discrepancy between $\pi$ and $q$. In effect, smokers could fail in two ways -- by harming their future selves and by imposing net externality costs on society.

Even if smokers do not accurately perceive the risks, it does not necessarily follow that their decisions are in error. consider the case in which individuals underassess the risks associated with smoking. It may be that even with an underassessment the decision to smoke would not be altered if the consumer's risk perception were replaced by the true probability $\pi$. Thus, the pertinent issue from the standpoint of efficient decision making with respect to risk information is whether risky decisions would be the same in the presence of better risk information or whether they would change.

Suppose that $S$ is the amount that an individual needs to be compensated in order to be made indifferent between smoking and non-smoking. In the case of people who prefer to smoke, the 
value of $\mathrm{S}$ is positive, whereas in the case of people who choose not to smoke the value of $S$ is negative so that they would be willing to pay some non-zero amount to avoid smoking. Suppose that evaluated at the true risk $\pi$, people would choose to smoke. Then $S$ is positive and satisfies the following condition

$$
(1-\pi) U(Y+S-P)+\pi V(Y+S-P)=W(Y) .
$$

If individuals underestimate the risk initially (i.e., $q<\pi$ ) but still would have a positive value of $s$ when evaluated at the true probabilities as in equation 3 , then cigarette smoking is still rational from the individual's standpoint.

If, however, $q$ is sufficiently below $\pi$ then the situation may arise in which based on the true risk of smoking it would not be rational to smoke. The value of $s$ evaluated at the time risk $\pi$ consequently will be negative.

This bias in consumer perspectives can potentially be reduced or eliminated through information provision. The government can convey information about the hazards of smoking so that individuals revise their subjective probability assessments $q$ for the smoking risks and increase them to a more appropriate level $\pi$. Nevertheless, even with accurate risk perceptions the expected societal loss term on the right side of equation 1 will not be incorporated in individual actions. What is needed from an economic standpoint is some mechanism to discourage smoking so individuals will, in effect, have the appropriate disincentive for smoking given the societal costs. This class of problems is the well known pigouvian externality situation in which an 
appropriate tax can lead individual economic actors to

incorporate the external effects of their decisions in their behavior. In addition, this tax may also serve the function of discouraging smoking in much the same way as would higher risk perceptions. Thus, a tax can both reflect the societal externality as well as the discrepancy between $q$ and $\pi$ in situations in which individuals underassess the smoking risk. The individual will choose to smoke in the presence of a tax $T$ if this tax satisfies

$$
(1-q) U(Y-F-T)+q V(Y-P-T)>W(Y) .
$$

This tax will lead to the same pattern of individual decisions as in the socially optimal situation characterized by inequality 1 if it is set appropriately.

The focus of the subsequent sections will be twofold. First, I will examine possible discrepancies between $q$ and $\pi$ and how these influence individuals' propensity to smoke. Second, I will address the wide range of externalities associated with smoking to ascertain their magnitude, direction, and relationship to an appropriate tax level.

3. Profile of the cigarette Tax Cigarettes are the most heavily taxed major category of consumer purchases. Relative to the purchase amount, tobacco products are subject to a higher tax rate than alcohol, three times the tax rate of gasoline, and over ten times the tax rate 
imposed on items such as utilities and automobiles. ${ }^{3}$

since roughly one-fourth American adults continue to smoke, the potential tax revenues associated with the cigarette tax are substantial." For the fiscal year ending June 30, 1993 this total of Federal, state, and municipal taxes on cigarettes was $\$ 12$ billion. ${ }^{5}$ This tax share is roughly equally divided bretween the Federal government and the states. The total Federal tobacco tax was $\$ 5.5$ billion in 1993, or an average of 24 cents a pack. The state tax total was $\$ 6.2$ billion, or 28.6 cents per pack. overall, the Federal and state taxes totaled 31.4 percent of the retail price of cigarettes. Municipal taxes added an additional $\$ 187$ million. Since almost all of the tobacco taxes are accounted for by cigarettes -- 98.7 percent in 1993 -- I will use the cigarette tax and tobacco tax label interchangeably. ${ }^{6}$

Although the absolute magnitude of cigarette taxes has never been higher than at its current level, these taxes have been higher as a percentage of the retail price. These taxes reached a peak of 51.4 percent of the total price of cigarettes in 1965,

3 These assessments are based on the calculations presented by Fullerton and Rogers (1993), p. 74. Their measure of the severity of taxation is the ratio of taxes paid to the value of gross purchases minus taxes paid. Based on this statistic, the implied tax rate in 1984 for tobacco is 0.79 , for alcohol it is 0.73 , for gasoline it is 0.26 , and for utilities it is 0.04 , and for automobiles it is 0.06 .

4 See Center for Disease control (1994).

5 These and other tax statistics reported in this paragraph are drawn from the Tobacco Institute (1993), page vii.

This percentage of the cigarette tax share is drawn from page 5 of the Tobacco Institute (1993). 
immediately after the initial government report on lung cancer and smoking. The percentage taxation varies over time because the tax is set in absolute amounts and is varied periodically. over the past 50 years, Federal cigarette taxes have held only five different levels, 7.0 cents per pack beginning in $1942,8.0$ cents per pack in 1951, 16.0 cents per pack in 1983, 20.0 cents per pack in 1991, and 24.0 cents per pack in 1993. The absolute level of the tax and the periodic nature of the tax revision has as a consequence resulted in swings in the cigarette tax percentage relative to retail price.

To assess the regressivity of cigarette taxes, Table 1 provides information on the distribution of taxes by income group. An introductory caveat is that one should be cautious in interpreting the incidence statistics for cigarette taxes since the income levels are based on reported income at a point in time. Income levels for lower income groups appear to be poorly measured, and these figures substantially understate the lifetime income levels for these groups. As shown in Poterba (1989), the lifetime incidence patterns of taxes tend to be more egalitarian than the cross-sectional statistics would suggest.

Even taking these cautionary observations into account, the patterns in Table 1 appear to be particularly stark. column two of Table 1 indicates the percentage of the different income groups who smoke. This percentage is a high 31.6 percent for those who make less than $\$ 10,000$ and has a low value of 19.3 percent for those who make $\$ 50,000$ or more. In terms of the 


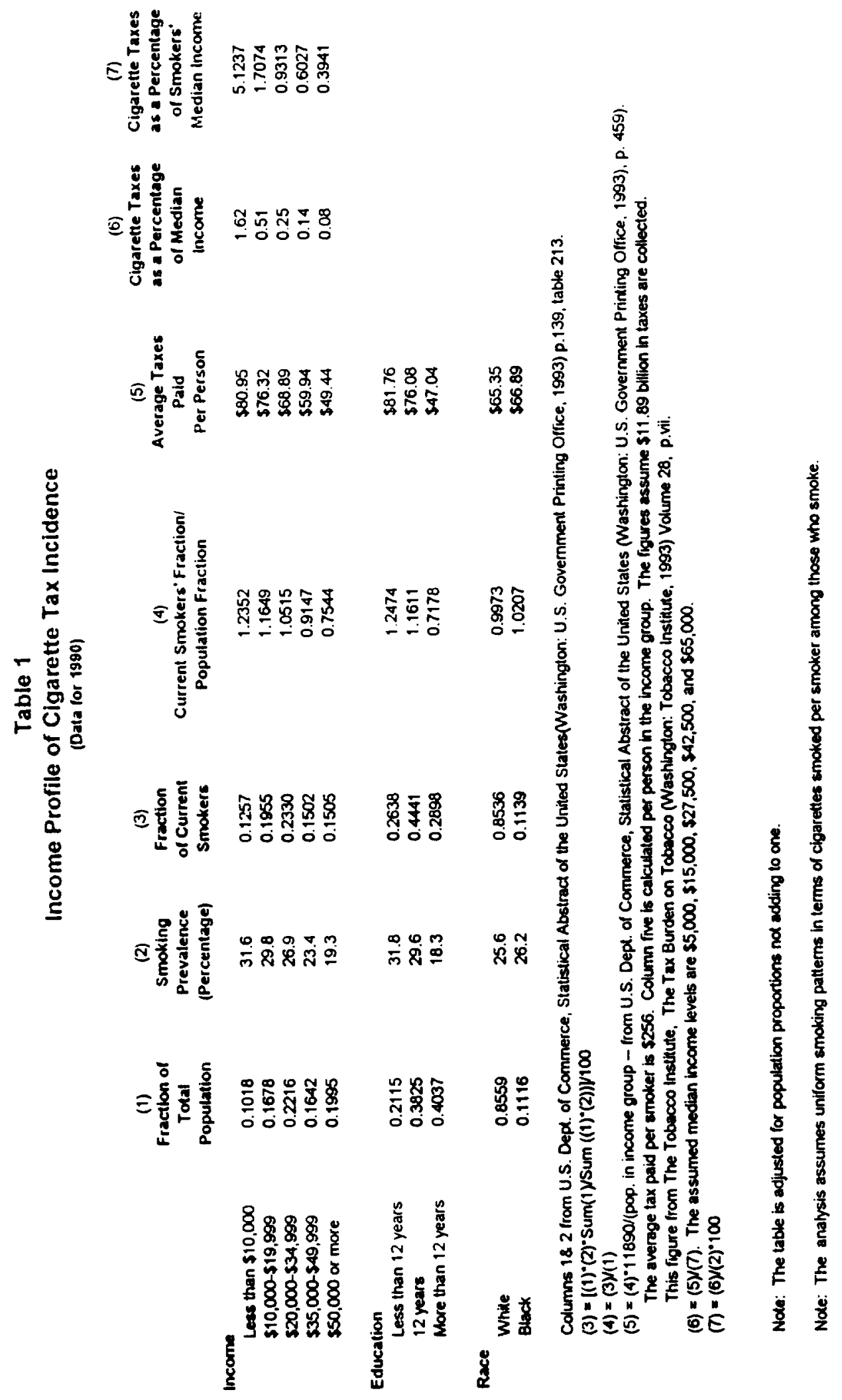


overall share of the smoking population, which is given in column three, both the smoking prevalence and the income group's share in the population are pertinent. For the income groups shown, the most frequently represented smoking group is the middle income range at $\$ 20,000-34,999$, but this is also the group with the largest fraction of the population.

A more pertinent statistic is the smoking fraction of the different income group relative to the fraction of the population represented by that income group. This ratio, which appears in column four of Table 1, indicates that the smoker ratio is highest for the poorer income groups and lowest for the upper income groups. This ratio ranges from 1.24 for those who make less than $\$ 10,000$ to 0.75 for those who make $\$ 50,000$ or more. For the three lowest of the five income groups shown in Table 1 , the relative smoking fraction of the group exceeds the population fraction, which is striking evidence of the income status correlation of smoking.

The average taxes paid for each person in the income group range from $\$ 49$ for those who make $\$ 50,000$ or more to $\$ 81$ for those who make less than $\$ 10,000$. The cigarette tax per person is consequently over one and one-half times as great for the poorest segment of the population when compared with the most affluent group. These absolute differences lead to even starker percentage differences, as is indicated in column six. As a percentage of individual income, cigarette taxes are negligible for those who make $\$ 50,000$ or more, as these taxes constitute 
under one-tenth of one percent of this group's income. In contrast, for those who make less than $\$ 10,000$, the cigarette tax amount averages 1.62 percent.

These calculations, however, understate the ultimate effect of cigarette taxes on those who pay them since they averacje the tax amount over the entire population in the income group, not simply smokers. If one focuses on column seven in Table.1, one finds that the cigarette tax percentage of the median income of smokers ranges from 0.4 percent for those who make $\$ 50,000$ or more to a percentage amount that is almost 13 times as great -5.1 percent for those who make less than $\$ 10,000$. Cigarette taxes are strikingly regressive.

Because of the strong correlation of income and educational levels, the educational breakdown of tax incidence shown in Table 1 follows a pattern similar to what one would expect based on the income breakdowns. The average taxes paid per person decline steadily with educational level, as these amounts exhibit a high value of $\$ 82$ per person for those with less than a high school education, and a low of $\$ 47$ per person with at least some college. The racial differences shown in Table 1 appear to be relatively minor, as blacks pay an average tax per person almost identical to that of whites.

The starkest distinction shown in Table 1 is the strong linkage of cigarette taxes to individual income levels. A negative feature of cigarette taxes is their regressivity. Since cigarette consumption is a decreasing function of income, even 
the total amount of cigarette taxes paid by the lower income groups is greater than that in upper income groups. Cigarette taxes are consequently regressive in absolute terms, not simply in proportional terms.

4. The Changing cigarette

The increased public concern with the risks of smoking has led to two major changes in the characteristics of cigarette smoking. First, cigarette smoking is much less prevalent now than it was in the past. Second, the kinds of cigarettes people smoke are quite different than those smoked decades earlier. In particular, the "tar" level, which is the most frequently used composite measure of the chemical residues linked to cancer risks of smoking, has declined as smokers have switched to lighter cigarettes. Many assessments of cigarette smoking have taken into account the changing frequency of smoking, but none of these studies has incorporated the shift in tar levels in these risk assessments.

This omission is quite fundamental, as it has broad ramifications for the assessed risks of smoking, the rationality of smoking decisions, and the magnitude of societal

externalities. Lower tar levels imply that the risk levels associated with smoking will be less than those that have been estimated. This discrepancy is not a minor nuance. The pertinent smoking era currently used for many risk assessments may be as much as a half a century out of date.

Two lags arise. First, the studies that are used in 
formulating the risk assessments often are not current, but instead have been undertaken a decade or more ago. Second, the smoking exposures that gave rise to the risks identified in these studies preceded the publication dates for these studies because of the substantial lag involved between exposure to carcinogens and incidence of the disease. If, for example, there is a three decade lag between cigarette smoking and the onset of lung cancer, and if the study estimating such a linkage is a decade old, then in effect there is a 40 year $l a g$ in the pertinence of the evidence.

In this section I will review the changing history of the tar levels of cigarettes and the implications of this shift for the potential riskiness of cigarette smoking. The adjustments that I will make will be linear, as reductions in tar will be weighted proportionally.' These adjustments are likely to be overly conservative to the extent that there is a no-risk threshold for carcinogenic exposures, which is consistent with much of the evidence on the causation of cancer. ${ }^{8}$

Figure 1 illustrates the shifting level of tar in cigarettes." The bottom trend, indicated as the "raw" data,

7 Evidence in support of the linearity of the dose-response relationship appears in the International Agency for Research on Cancer (1985).

${ }^{9}$ For discussion of the zero or minimal risks posed by low levels of carcinogens, see Ames and Gold (1993), especially pp. 154-157. Also see Cothern (1992).

9 The tar data for 1954 and for 1968-83 are from the center for Disease Control (1989), p. 21. Data for 1955-67 are from U.S. Department of Health and Human Services (1981), p. 207. 


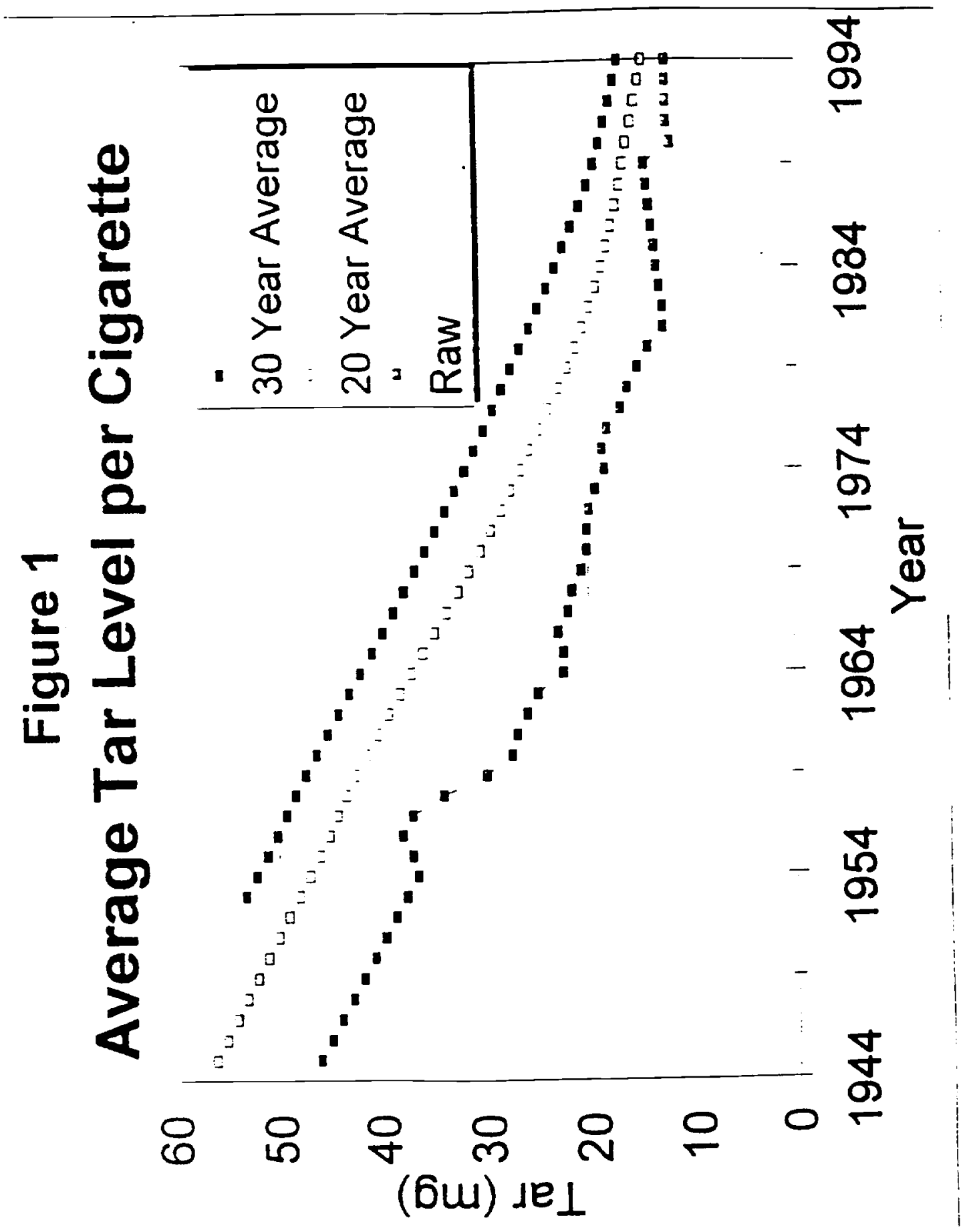


pertain to the average level of tar in cigarettes observed in that year. These levels were estimated to be $46.1 \mathrm{milligrams}$ of tar per cigarette in 1944, which dropped to 12 milligrams of tar by 1994 .

Figure 1 also illustrates the 20 year and 30 year average of these tar levels, where these averages are for the 20 and 30 year period preceding the date indicated. These moving averages indicate higher average tar levels of cigarettes and smoother declines. Examination of these 20 and 30 year averages is potentially more pertinent to the extent that it is a weighted average of exposure amounts over a long period of time that generates the risk rather than point estimates of the risk level. All of the results in Figure 1 pertain to risk levels at a period of time, taking into account only those lags explicitly indicated. If the lag structure is somewhat different, as for example would be the case if risk exposures in the past decade did not affect one's probability of cancer but those in the two previous decades did, then one would want to utilize a different weighting process.

The raw average tar levels of cigarettes display a slight increase in the $1980 \mathrm{~s}$ in Figure 1. This trend is attributable at

Data for 1984-1993 are derived by running a regression of average tar levels on the percent of cigarettes with less than $15 \mathrm{mg}$ of tar $(1967-83)$ and using the resulting coefficient to estimate tar levels. Data for 1923-53 are derived by running a regression of average tar levels on year and using the resulting coefficient to estimate tar levels. The data on percent of cigarettes with less than 15mg of tar are taken from the U.S. Federal Trade Commission (1992), pp. 28-30. 
least in part to the rising market share of generic cigarettes. Generic cigarettes have a higher average tar level than premium brands, contributing to the observed pattern.

Figure 2 indicates the implications of these tar adjustments for the potential riskiness of cigarette consumption. Those figures represent smoking levels per capita, where the base is the entire adult (age 18 and above) U.S. population, not.simply the smoking population. The unadjusted data appear at the top of Figure 2 , as the number of cigarettes consumed per capita rose until 1964, which is the year in which the U.S. Department of Health, Education and Welfare issued its landmark report on lung cancer and smoking. ${ }^{10}$ Cigarette consumption continued to decline at a moderate pace until around 1983, after which consumption of cigarettes has decreased more starkly.

The bottom pattern of cigarette consumption in Figure 2 makes a tar adjustment, relative to the tar levels in cigarettes in 1944. Whereas unadjusted cigarette consumption was rising for the next two decades, the tar-adjusted cigarette consumption levels were on the decline. This decrease occurred long before the advent of on-product cigarette warnings, television and radio ad bans, and the concern over environmental tobacco smoke. Indeed, the pattern of tar-adjusted smoking exhibits a fairly steady decline over the 1944-1984 period.

one of the steepest periods of decline in the tar-adjusted

10 see the U.S. Department of Health, Education and Welfare (1964). 


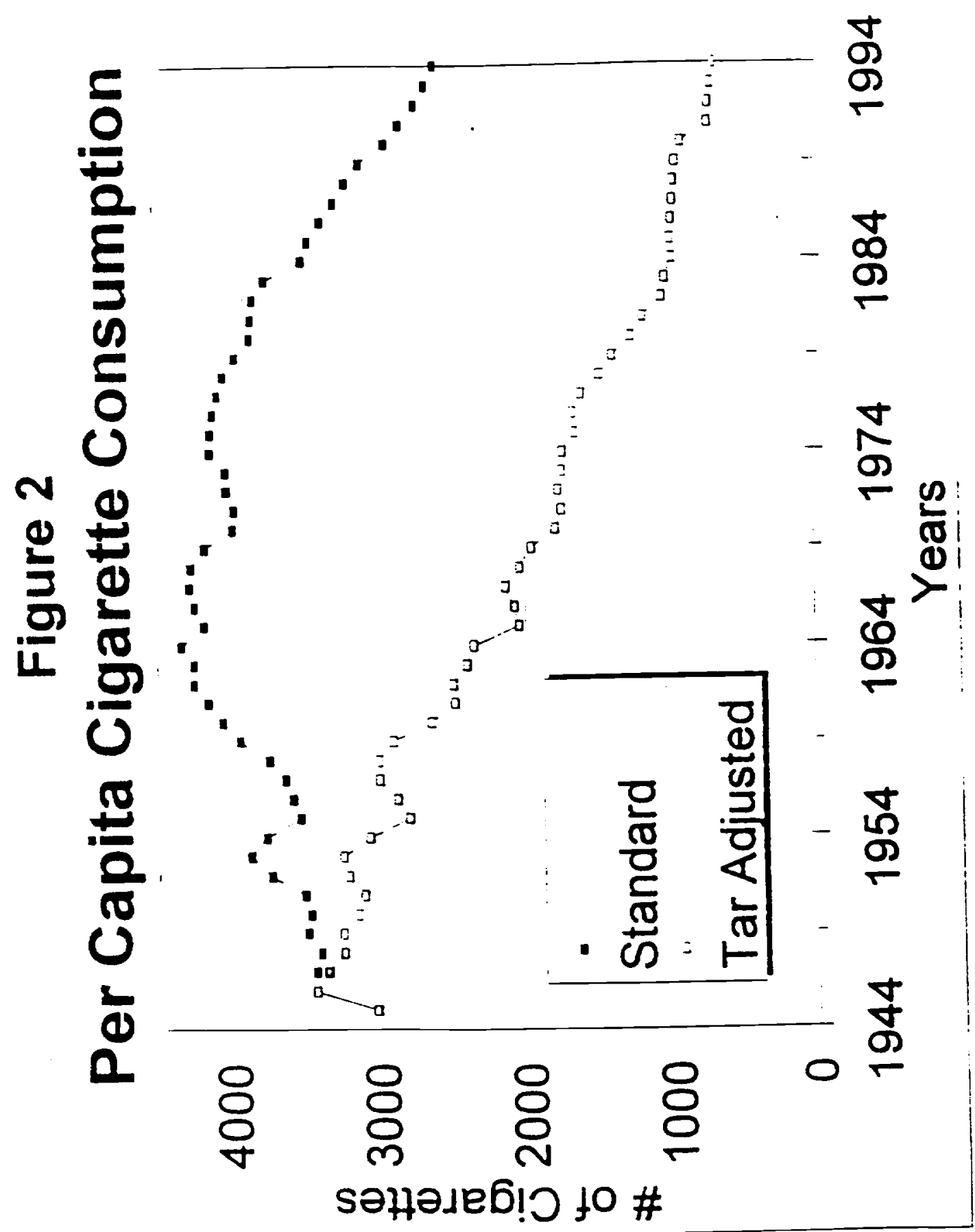


cigarette consumption and in the average tar levels per cigarette shown in Figures 1 and 2 was 1957 to 1960. This was the era of the "Great Tar Derby" in which the cigarette companies undertook an advertising war to highlight the tar and nicotine levels of their cigarettes. ${ }^{11}$ This market-based competition led to advertising claims, such as "Today's Marlboro--22 percent less tar, 34 percent less nicotine." The ban on tar and nicotine advertising enacted by the Federal Trade Commission in 1960 halted the dramatic decline in tar-adjusted levels of cigarettes, leading to the flattening of the decline shown in Figure 1 and 2 . The main implication of Figure 2 is that the tar-weighted cigarette consumption has followed a quite different pattern than overall per capita cigarette consumption and should lead to a quite different interpretation of smoking trends. The decline in the risk-weighted cigarette consumption is not as recent a phenomenon as the raw per capita cigarette consumption figures would suggest. Tar-adjusted per capita cigarette consumption has been on the decline for almost the entire past half century. Moreover, because of the linkage of cigarette risk estimates to tar levels, these estimates must be revised to reflect the tar content in order to be pertinent to the changing character of cigarettes.

Figures $3 a-3 c$ indicate the smoker's lifetime tar-weighted cigarette risks assuming various different lags between cigarette

${ }^{11}$ For further discussion of the Great Tar Derby see Viscusi (1992b) and Calfee (1986). 


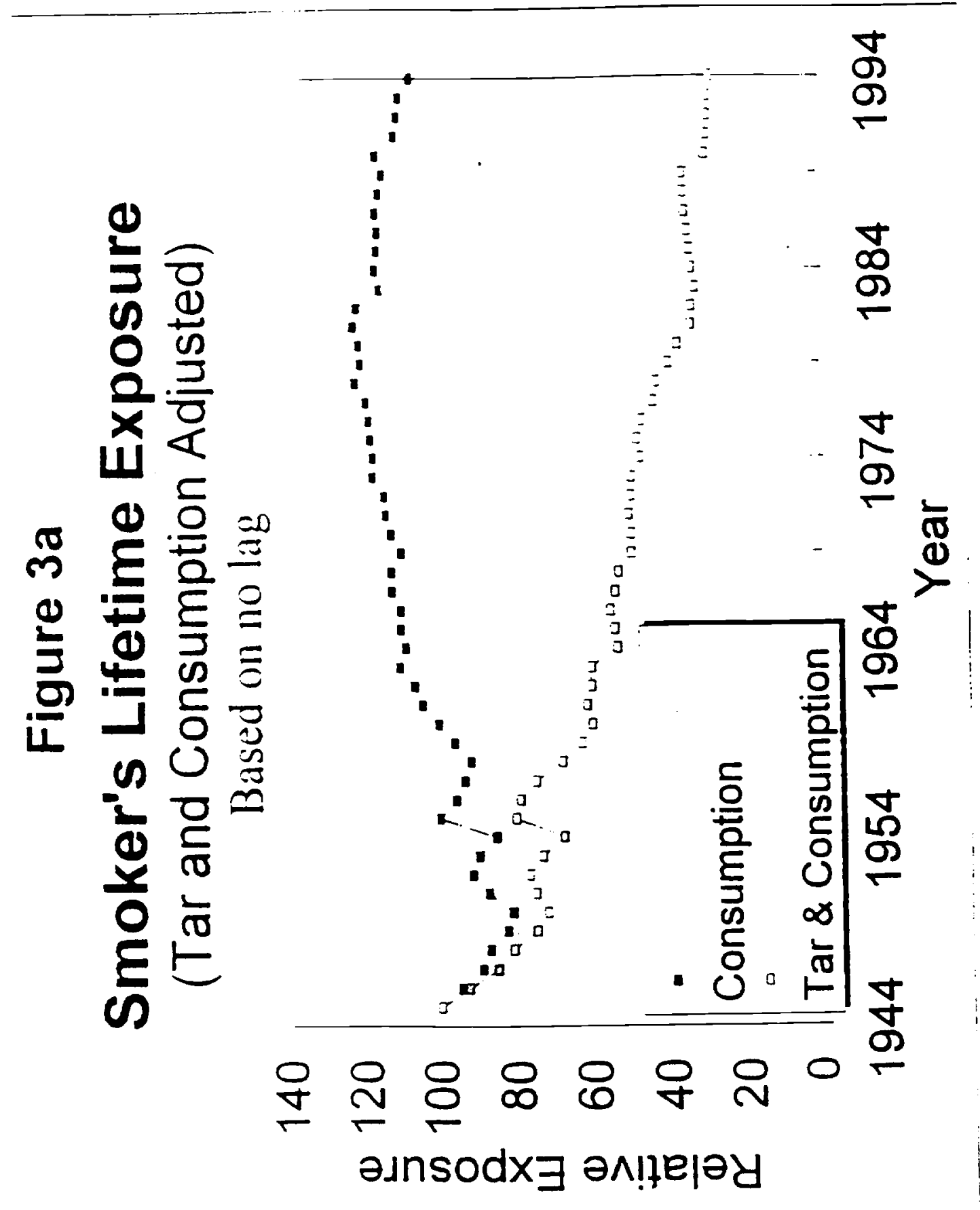




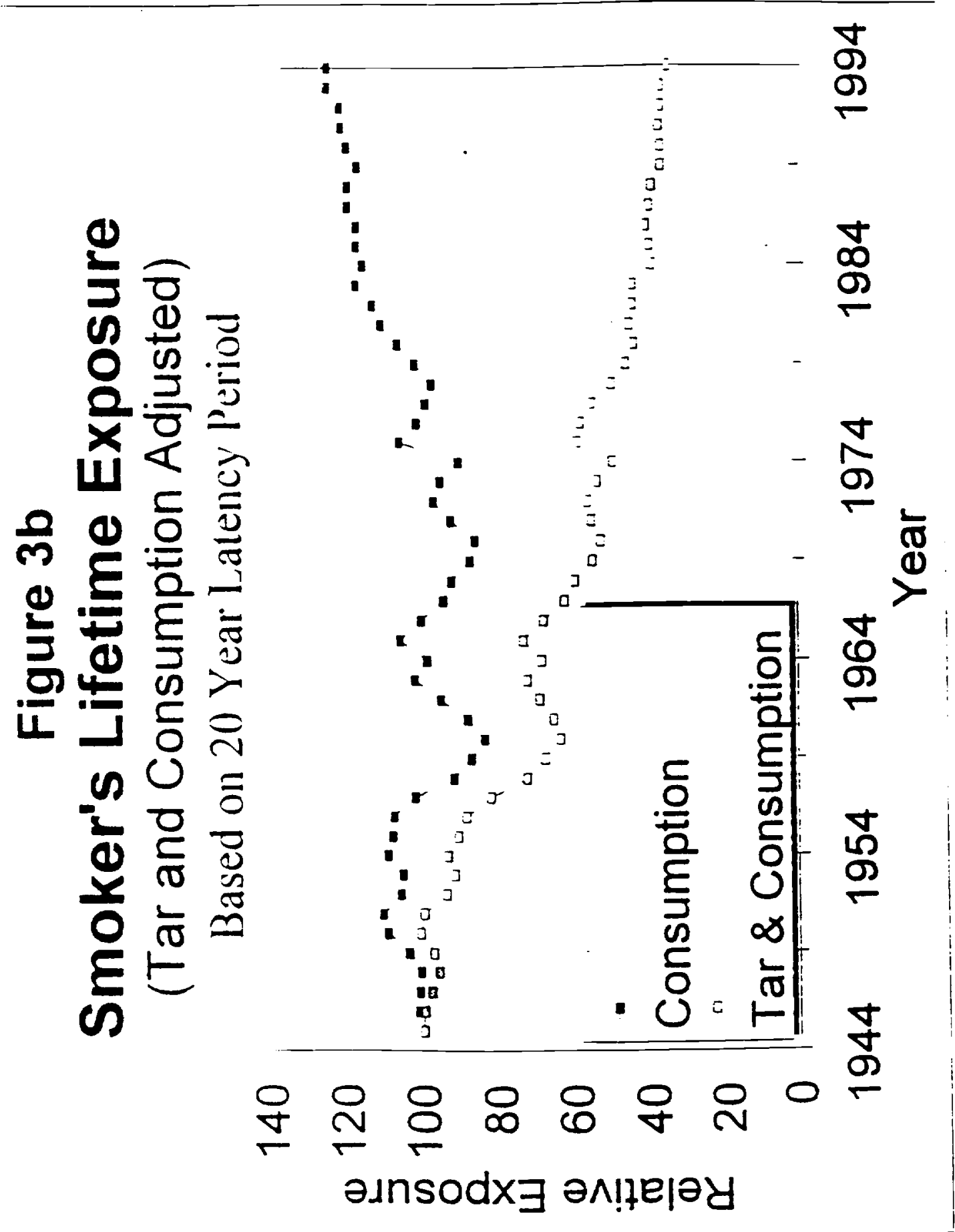




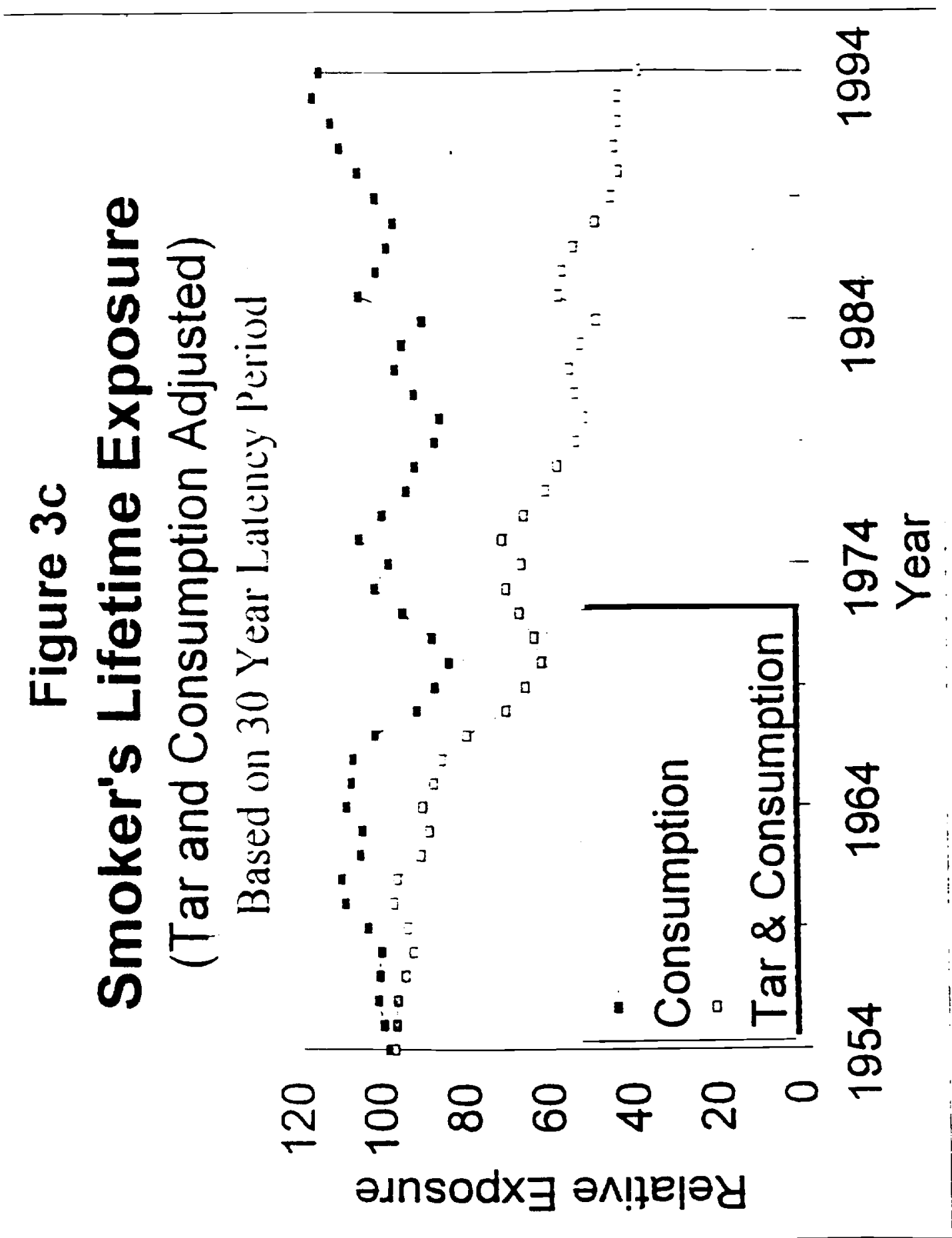


consumption and the generation of the risk. Whereas Figure 2 presented data per capita for the entire population, the data in Figure $3 a$ are per capita, where the baseline population consists of smokers only. These figures account for changes in the number of cigarettes smoked as the tar level changes but not whether each particular cigarette was smoked more intensively. Figure $3 a$ is based on risks being contemporaneous; Figure $3 \mathrm{~b}$ incorporates a 20 year latency where there is a fixed lag of exactly 20 years not a distributed lag over a twenty year period; and Figure $3 \mathrm{C}$ incorporates a 30 year latency period. For example, the risks in Figure 3b for 1964 arose from smoking in 1994. In each case, the trends are indexed so that the relative exposure amount is 100 in 1944.

There is a wide discrepancy between the adjusted and unadjusted lifetime exposure levels for cigarettes in 1994 . However, the spread between the adjusted and unadjusted trends is starkest at an earlier date in the case of the unadjusted figures, as recognition of a 20 year latency period narrows the gap between the adjusted and unadjusted figures, particularly through the first three decades, and there is a further narrowing of these early trends in the case of the 30 year latency period. The extent to which the lifetime risk is consequently going to be affected by taking into account the tar and consumption levels will consequently will depend both on the era in which the risk assessments are made as well as the lag assumption that is made. 5. Externalities to One's Future self 
If smoking decisions do not satisfy the efficiency properties outlined in section 2 from the standpoint of individual rationality, then there will be a market failure. If, for example, smokers underestimate the risk and smoke in situations in which they would not do so j.f fully informed, then the resulting risk level will be inefficient. Schelling (1984) refers to these errors as externalities to one's future self because there is a time lag before the adverse effects of smoking will become apparent. What shelling suggests is that one's future self may make different decisions than one would make if fully apprised of the long-term consequences of smoking.

There are several ways in which decisions might err. For example, some observers have hypothesized that even if people understand the risk of smoking they may not appropriately value the health consequences of smoking or may be addicted to smoking and unable to alter their behavior. I explore these issues in detail elsewhere in Viscusi (1992a), but it is worthwhile to summarize some of the principal empirical results that suggest that smoking behavior follows patterns similar to that of other types of consumption goods. The price elasticity and income elasticity estimates for the demand for cigarettes are similar to those for other products. These elasticity values, which have been documented in dozens of studies for several countries, range from a negative price elasticity from -0.4 to a price elasticity 
for teenagers of $-1.4 .^{i 2}$ Becker, Grossman, and Murphy (1994) also find that the long run elasticity is greater than the short run elasticity, which is consistent with their model of rational addiction.

The character of the tradeoffs that smokers make in other contexts is also consistent with risk-taking decisions in the smoking domain. In situations involving job hazards, smokers require compensation per expected job injury of $\$ 26,100$, whereas the average worker receives compensation of $\$ 47,900$ per statistical injury. ${ }^{3}$ The group most averse to risks, nonsmoking individuals who also wear seatbelts, receive compensation per expected injury of $\$ 83,200$. The sorting of workers in the labor market and the matching up of individuals to jobs of different risk with their corresponding levels of compensation consequently follows the patterns one would expect. Smokers tend to be at the lower end of the range in terms of their implicit value of job injuries. This relative standing is also corroborated by the results in Ippolito and Ippolito (1984), who found that the implicit value of life reflected in smoking behavior was in the range of $\$ 300,000$ to $\$ 600,000$ in 1980 , which is similar to the implicit values of life displayed by workers who have matched themselves to relatively high risk jobs. ${ }^{14}$

${ }^{12}$ A comprehensive review of this literature appears in Viscusi (1992b).

13 See Viscusi (1992) and Hersch and Viscusi (1990).

${ }^{14}$ For a survey of the value of life literature, see Viscusi (1992a, 1993). 
The smoking propensity response to higher risk perceptions is also consistent with rational decision making. Higher assessed smoking risk probabilities decrease the probability that an individual will smoke. Estimates in viscusi (1992b) of this linkage indicate that if current average lung cancer risk perceptions were decreased from their level of 0.43 to a value in the estimated risk range based on earlier scientific evidence of $0.05-0.10$, then societal snoking rates would rise from 6.5 percent to 7.5 percent.

There is also evidence of responsiveness in terms of the kinds of cigarettes selected. ${ }^{15}$ Individuals who express concerns about the health consequences of smoking are much more likely to smoke low tar cigarettes (less than or equal to three milligrams tar per cigarette), as 87.1 percent of those who smoke low tar cigarettes indicate such health concerns. In contrast, individuals who smoke high tar cigarettes (greater than or equal to 21 milligrams tar per cigarette) are much less likely to express concern with the health risks of smoking, as only 54.8 percent of this group indicates concern.

The primary focal point of my discussion will be on whether smokers accurately perceive the risks of smoking. The two sets of survey data I will use pertain to the years 1985 and 1991. The key issue is whether smokers' risk beliefs in those years were as high as would be warranted based on the scientific evidence at that time.

is See Viscusi (1992b). 
In assessing the accuracy of the risk perceptions one must first establish the scientific reference point that will be used to ascertain the true estimated risks of smoking. The surveys focus on both lung cancer risks and total mortality risks so that estimates are needed for each of these risk groups. In addition, I make adjustments for the changing per smoker consumption of cigarettes since individuals may, for example, smoke more cigarettes if they have switched to lower tar cigarettes. Table 2 summarizes the sensitivity of the mortality estimates to the changing level of tar in cigarettes. The three pairs of columns pertain to the lung cancer risks, the overall mortality risk after making a tar adjustment for lung cancer, and the overall mortality risk making tar adjustments for all risks. Results appear for both 1985 and 1988. The scientific reference point that will be adopted utilizes the adverse health effect estimates presented in the annual reports by the U.S. Surgeon General. ${ }^{16}$ The first row of risk estimates pertains to the risk estimated using scientific data available at the time of each of the survey years. These data are not adjusted for changes in tar levels. Both low and high estimates of the risk range appear in each instance. The most recent data available for the survey year 1991 is based on 1988 studies. In the case of lung cancer, the estimated lifetime incremental risk due to smoking ranged from

$: 6$ Further details explaining the nature of my calculations using these data appears in viscusi (1992b). In my earlier treatment I only considered the unadjusted figures, ignoring changes in tar levels. All of the adjusted estimates are new. 


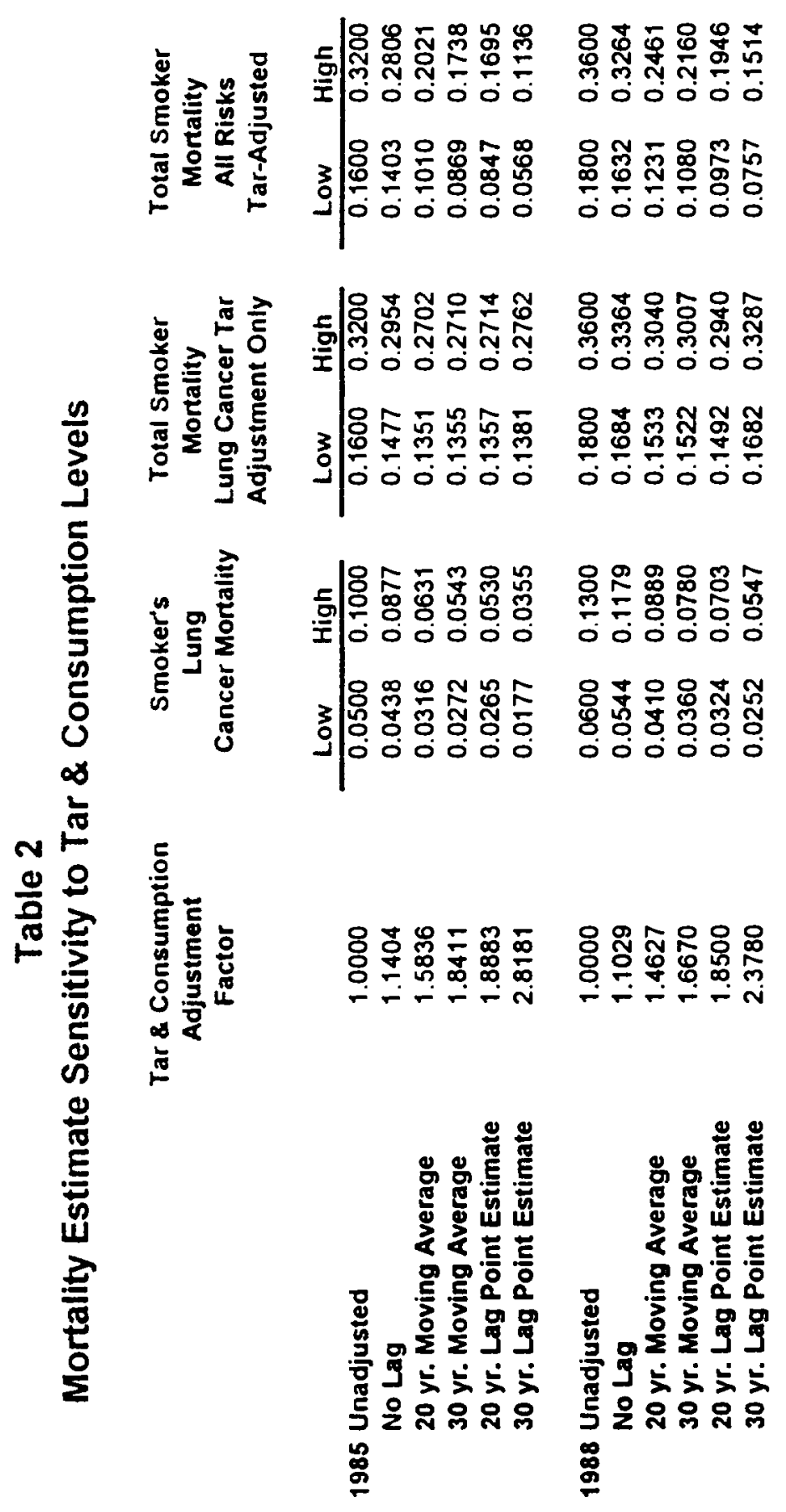


0.05 to 0.10 in 1985 and from 0.06 to 0.13 based on 1988 evidence. The total smoking mortality amount is roughly triple the lung cancer risk, as it ranges from 0.16 to 0.32 in 1985 and from 0.18 to 0.36 in 1988 .

Three sets of mortality estimates appear in Table 2 . The first set pertains to lung cancer and the adjusted lung cancer mortality rates. The second set of estimates addresses total smoking mortality, with tar adjustments for only the lung cancer component of total mortality, thus understating the potential role of tar adjustments. The final pair of columns in Table 2 makes tar adjustments for all mortality components, which will tend to overstate the effect of shifts in tar levels. The effect of the tar adjustments is substantial. In the case of lung cancer, the change in the risk levels based on point estimates of the risk, ignoring lags in the generation of the risk would be to decrease the risk range to $0.04-0.09$ in 1985 and from 0.05 to 0.12 in 1988. If, however, lung cancer risks are generated by a moving average or by a lag, then the risk levels that have been estimated by the surgeon General will have been generated by exposures to much higher levels of tar than are present in the cigarettes today. Making the adjustments for the 20 year moving average or a 30 year moving average decrease the estimated lung cancer risk by 0.02 so that the risk is approximately cut in half by the 30 year moving average. If the risk is generated by the point estimate of the exposure 20 or 30 years before the surgeon General study, then the lower end of the 
1985 risk range is reduced to 0.03 in the 20 year case and 0.02 in the 30 year case. In effect, one can eliminate up to twothirds of the lung cancer risk level by making an appropriate adjustment for the tar levels of cigarettes.

The adjustments in the case of total smoking mortality are less in relative terms when only the lung cancer component is adjusted. Even in the 30 year lag point estimate case, the 1985 risk range drops from $0.16-0.32$ to a range of $0.14-0.28$, which is a very modest decline. If, however, all mortality components are adjusted for changing tar levels, the corresponding 1985 risk range becomes $0.06-0.11$. The shifts for the 1991 risk estimates follow similar patterns.

The reported risk levels are considerably higher than any of these estimates of the risk. The results reported in Table 3 are based on a national survey of lung cancer risk perceptions in 1985 and a North Carolina survey that I undertook in 1991, each of which are reported in Viscusi (1992b). The national smoking survey asked respondents how many out of 100 smokers would get lung cancer because they smoked, where these responses been converted to a fraction for the purposes of reporting in Table 3. My 1991 survey questions alter this wording somewhat, asking about the lung cancer fatality risk level rather than the lung cancer incidence level and asking respondents about the total smoking mortality risk.

In each case, the risk perceptions are substantial. Smokers estimate the lung cancer risk as being 0.37 and the lung cancer 
Table 3

summary of smokers' Risk Perceptions

Risk perception

Lung cancer risk (1985)

Lung cancer fatality risk (1991)

Total smoking mortality risk (1991)

Source: Viscusi (1992, pp. 69 and 77).

\section{Full sample}

0.43

0.38

0.54
0.47

Smokers

0.37

0.31 
fatality risk as 0.31 , where each of these estimates is roughly five to 10 times larger than the various adjusted lung cancer mortality risk estimates shown in Table 3. Similarly, the overall smoking mortality estimate of 0.47 indicates that smokers believe the risk of death from smoking is almost a 50-50 proposition, unfavorable odds that are considerably more adverse than anv of the risk estimates shown in the final columis in Table 2 .

one particularly controversial group in society is that of younger smokers, since many smoking critics believe that these individuals will begin smoking at a young age and be discouraged by the transactions costs of changing smoking from altering their behavior. Whereas the popular belief is that the young underassess the risk of smoking, in fact the opposite is the case. Indeed, younger smokers overestimate the risks by more than do their senior counterparts. In the case of the 1985 national survey, respondents aged 16-21 assessed the average lung cancer risk as being 0.49 , or a value that is 0.06 greater than that for society as a whole. Smokers in this younger age group assess the lung cancer risks as being 0.45 , which is 0.08 greater than that of the entire smoking population. These results are not entirely surprising since they reflect the different $\mathrm{mix}$ of smoking information and the different social context of smoking in recent years. Indeed, even pre-teens are extremely sensitive to the potential risks of smoking as they believe almost 
unanimously that smoking is a cause of cancer. ${ }^{17}$

The final rationality issue to be explored is whether smokers understand the extent of the life that will be lost should they die because of their smoking behavior. My 1991 estimates of the life expectancy loss indicate that the overall societal assessment of the expected loss in life expectancy due to smoking is 11.5 years, with smokers assessing the expected life expectancy loss at 9.0 years. Based on the original 1988 estimates of the mortalities shown in Figure 2 , one calculates a scientific reference point of an expected life expectancy loss of 10.9 years for smoking females and 6.9 years for smoking males. ${ }^{18}$ These figures are below the assessed life expectancy loss amounts. Adjustments for tar and cigarette consumption levels by making the same proportional adjustments to the mortality loss as for total smoking mortality in Table 2 would reduce the scientifically estimated life expectancy loss further and increase the extent of the overestimation of the life expectancy loss.

overall, there is little evidence that individuals confer an adverse externality on their future selves through their smoking

17 Indeed, 99 percent or more of all age groups ranging from seven to 14 believe in the smoking lung cancer causal link. See Viscusi (1992b) for additional discussion.

18 These life expectancy loss estimates are derived in Viscusi (1992b). More recent 1993 estimates of the life expectancy loss, given that a death is smoking-related, imply that eight years loss of life is lost than is assumed in the scientific reference point estimates discussed in the text. These new data are discussed below. 
behavior. All the available empirical evidence is suggestive of decisions being made in a rational and consistent manner. Although this evidence is not conclusive, the diverse array of information that we have on a wide variety of aspects of snoking decisions, risk perceptions, and smokers' behavior in other contexts conveys a quite consistent picture of smoking behavior. Such behavior may have broader implications for other kinds of externalities as well, not simply those to the smokers' future self. Theories of the household typically assume that the household heads make decisions on behalf not only of themselves but also on behalf of other family members. Thus, the husiond or wife would take into account his or her own welfare when making the smoking behavior as well as the implications that the smoking behavior would have for the well-being of other family members. ${ }^{19}$ If individuals do in fact internalize these intrafamily externalities, then they will be already reflected in the individual decisions. Rational individual decisions consequently will imply that household externalities are internalized as well and need not be considered. As a result, the discussion below will indicate the value of the household externalities in the case of environmental tobacco smoke, but it will not treat these as societal externalities since rational smokers will internalize these costs in making their smoking decisions. Since the cost of these externalities will be explicitly assessed, those who wish to undertake sensitivity analyses by classifying these costs in a

19 See Becker (1991). 
different manner can readily do so.

6. Insurance Externalities of Smoking

A particularly controversial class of externalities linked to smoking consists of the insurance cost effects arising from the estimated health consequences of smoking. States such as Mississippi are initiating law suits in attempt to recoup state Medicare payments. Hillary clinton and the clinton Administration more generally have used the argument that cigarette smoking leads to higher health insurance costs as a rationale for a higher cigarette tax. There has also begun to develop a growing sense in the media that smokers are not paying their own way.

This perception contrasts with the results of economic studies of externalities. Assessments by Shoven, et.al. (1987), Manning, et.al. (1989), and Gravelle and $\mathrm{zimmerman}$ (1994) all suggest that consideration of the insurance-related externalities is more complex than many public observers have noted. In particular, if smoking indeed leads to premature death, then there will be competing influences. Higher health care costs may be imposed in the short-run, but these deaths may save society additional resources later in life since these smokers will not be able to collect social security and pension benefits for the same amount of time. Which effect is larger is an empirical issue. Moreover, when assessing these externalities, it is certainly not appropriate to tally only the potential adverse consequences of smoking, such as the effects on Medicare or 
health insurance costs, and to systematically neglect the estimated cost savings to society. Proper assessment requires that all legitimate effects of these type be considered. The most comprehensive study to date is that by Manning, et.al. (1991), which also form the basis for much of the analysis in Gravelle and Zimmerman (1994). The approach here will be to take the Manning, et.al. (1991) study as the baseline and to update it in a variety of ways. These revisions will include much more than recognition of price changes through shifts in the Consumer Price Index. Rather, using their study as a baseline, the estimates were completely reworked to reflect the changing cost of health insurance as well as our increased understanding of the role of smoking. Because these changes are so extensive and do not involve any conceptual controversies, discussion of the procedure is relegated to the Appendix.

Table 4 reports the external insurance costs per pack of cigarettes for two different cases, one in which there is no adjustment for changes in tar level of cigarettes and a second in which the tar and per capita consumption adjustment is made. The situation in which there is no tar adjustment closely parallels the Manning, et.al. (1991) analysis in that there is no consideration of the changing character of cigarettes, but there is adjustment for all the different cost factors that have changed since the original Manning, et al. study. ${ }^{20}$ These

${ }^{20}$ The baseline results from Manning, et al. (1991), Table 4.15 , pertain to lifetime costs of smokers minus lifetime costs of nonsmoking smokers. 


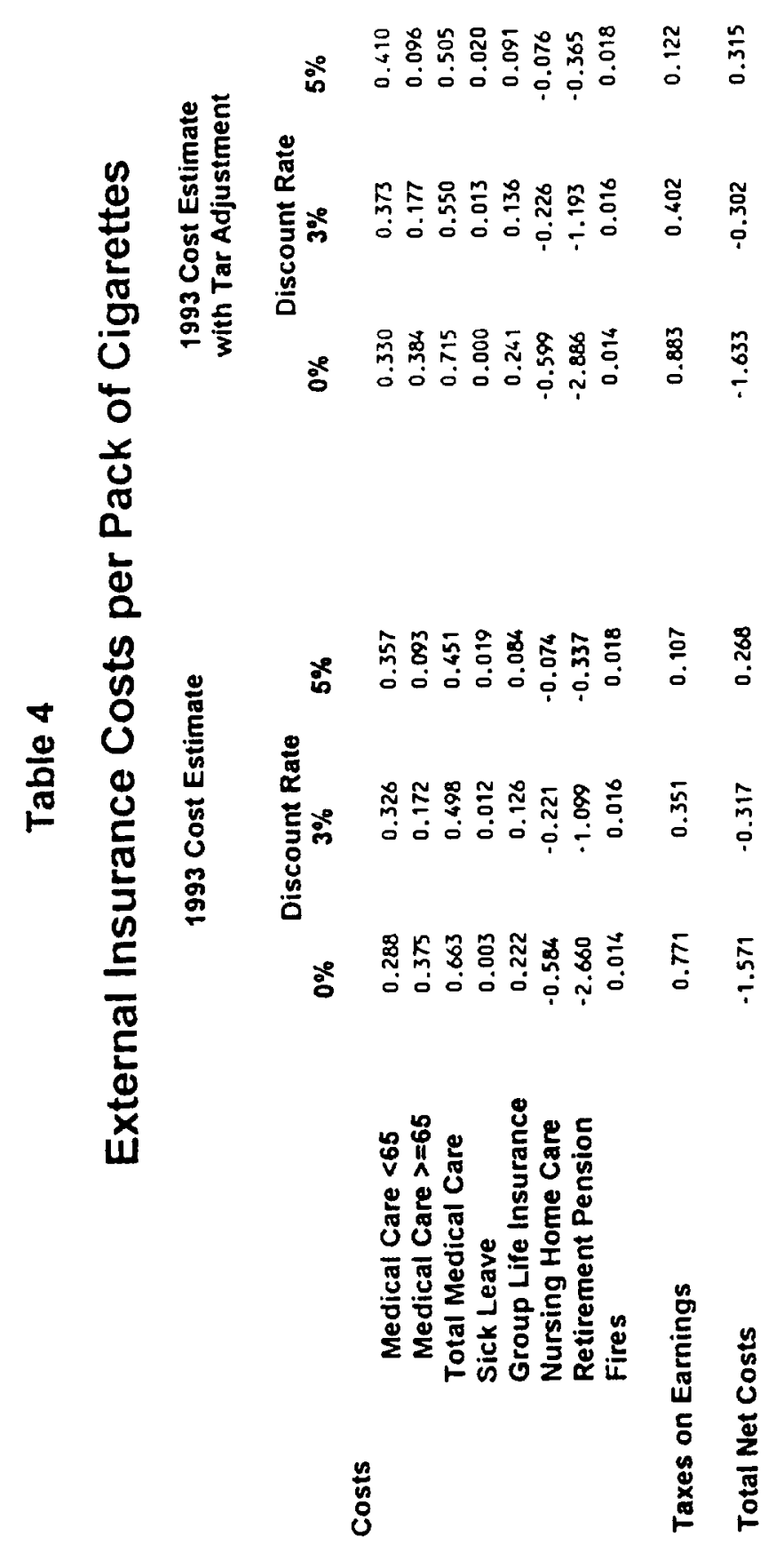




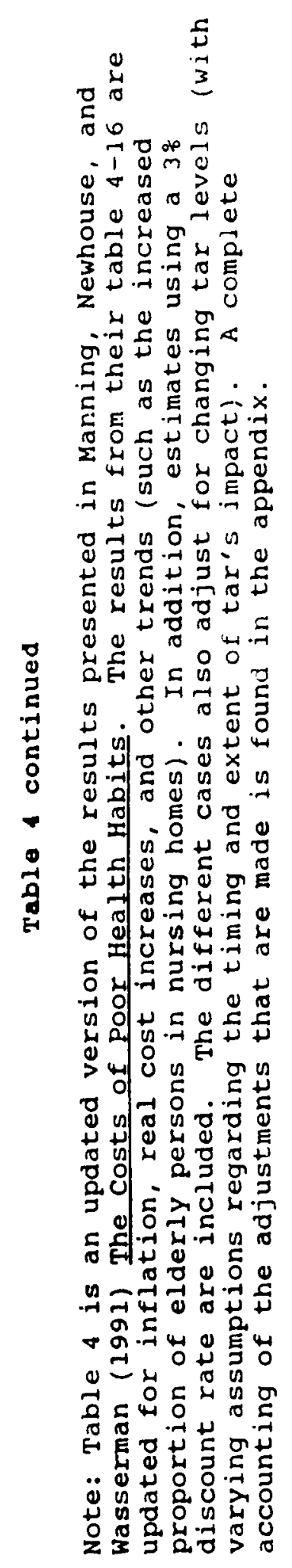


adjustments are nontrivial. In the zero discount rate case, simply updating the Manning, et.al. (1992) findings based on the shift in the Consumer Price Index would lead the external insurance cost per pack of cigarettes to be $-\$ 1.19$, whereis after making all the various adjustments shown in the Appendix the 1993 cost estimate at the 0 percent discount rate it is $-\$ 1.63$. The cost savings that smokers provide to society are consequently higher with my estimates than with the simple update of the Manning et.al. estimate. If one were to use a discount rate of 5 percent, there are net costs imposed on society, and these would be higher under my formulation. With a tar adjustment, tliese costs per pack are $\$ 0.32$, whereas an update of the Manning study would have made these costs per pack equal to $\$ 0.27$.

Estimates appear in Table 4 for three different discount rates, where the most reasonable rate corresponding to the long run real rate of return in the U.S. economy is 3 percent. The discount rates above and below that amount are intended to indicate the sensitivity of the results to the discounting assumption. For concreteness, let us focus on the results for the 3 percent discount rate after making the tar adjustment. The findings in Table 4 are particularly instructive in indicating which of the externalities are most consequential. The added cost that smokers generate in terms of medical care costs under the age of 65 are $\$ 0.37$ per pack, and there is an additional cost of $\$ 0.18$ per pack after age 65 , so that the total added medical care costs is $\$ 0.55$ per pack. Sick leave costs are negligible, 
as these are under 1 cent per pack. Group life insurance also reflects a higher cost amount since smokers die sooner than their nonsmoking counterparts, so that this value is $\$ 0.14$ per pack. Smoking also leads to an additional cost of fires of just under $\$ 0.02$ per pack.

The main areas of cost savings are nursing home care and retirement pensions. Since smokers die sooner, they will spend less time in nursing homes, leading to a cost savings of $\$ 0.23$ per pack. In addition, they will be collecting their pensions and social security benefits for a shorter period, leading to a cost savings of $\$ 1.19$ per pack. Since smokers die sooner, society looses the taxes it could have reaped on their earnings. The health and Social security tax losses from these effects average $-\$ 0.40$ per pack. The total net costs of smokers to society are $-\$ 0.30$ per pack. The fire costs in Table 4 reflect only the insurance costs, which adjusted Manning, et al.'s (1991) estimates to account for current estimates of fire-related damage. Subsequently, fire-related mortality costs outside the home will be added as well, which is another new feature of this study.

Table 5 extends these analyses to consider various time lags. In the case of the 30 year lag point estimates, one obtains very similar results to what was found above. Including lost taxes on earnings as an externality as well as the other insurance-related costs, one has a total net cost of smokers to society of $-\$ 0.23$. If taxes on earnings are excluded from 


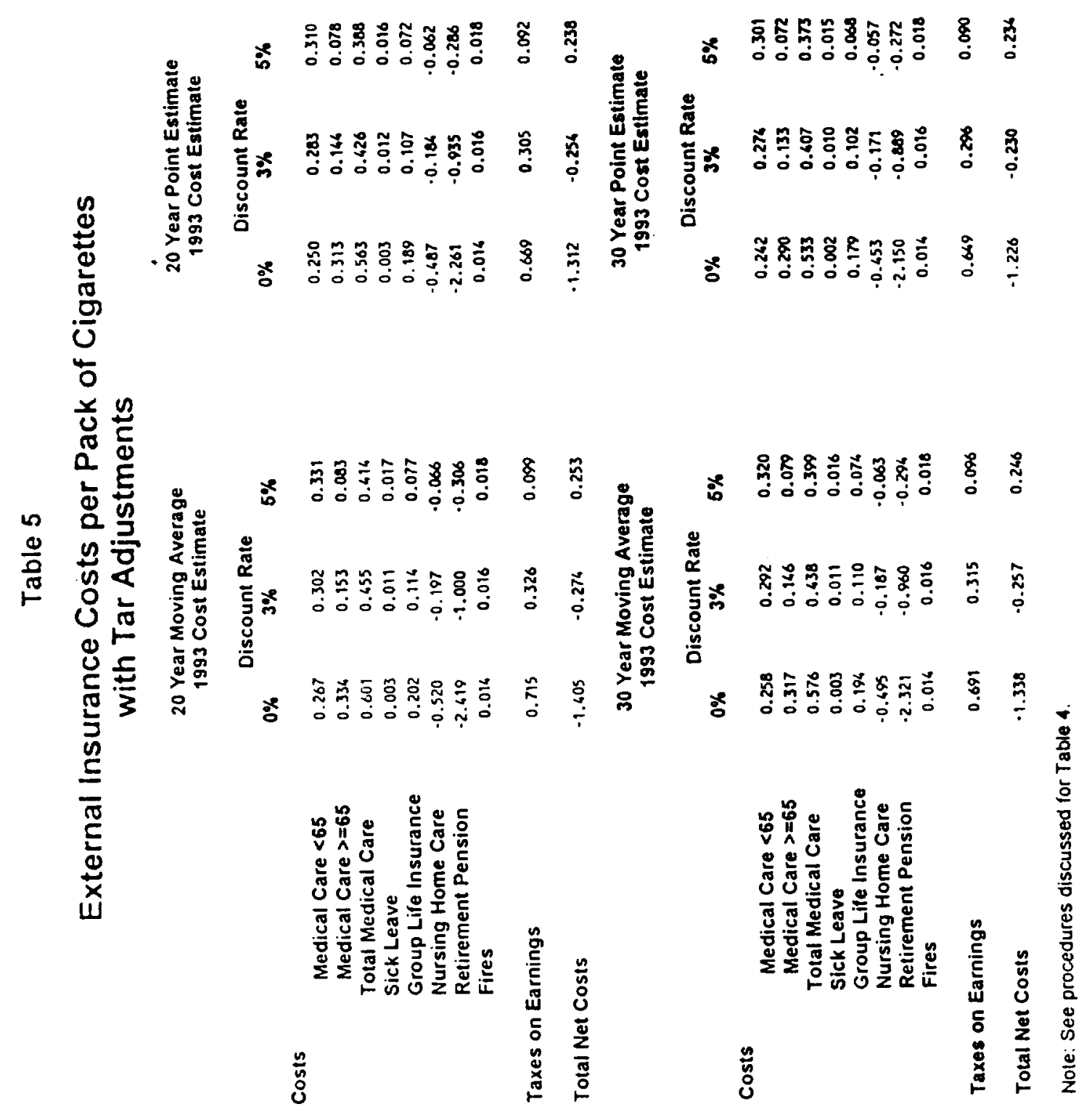


consideration, the net externality cost at a 3 percent interest rate is $-\$ 0.53$. In effect, smokers are already paying their own way in the sense that there is a net externality cost savings to society from their smoking because of the cost savings arising from their premature deaths. These figures exclude from consideration the cigarette taxes already paid by smokers. Thus, there is a net cost savings from the externalities as well as an additional infusion of tax revenues from smokers. Taken at face value, these estimates indicate that if one were to set the Pigouvian tax amount based on the 3 percent discount rate results, that cigarette smoking should be subsidized rather than taxed.

\section{Environmental Tobacco Smoke}

Perhaps the most controversial class of external effects pertaining to smoking is environmental tobacco smoke. Long regarded as a nuisance by many nonsmokers, environmental tobacco smoke health risks have now become an object of considerable social controversy. Both the U.S. Occupational safety and Health Administration and members of the U.S. Congress, with the support of a report by the U.S. Environmental Protection Agency, have proposed taking initiatives against environmental tobacco smoke. In each case, these agencies have suggested that there is a causal link between environmental tobacco smoke and adverse health outcomes, such as lung cancer and heart disease.

In contrast, previous assessments of the external costs of smoking have not included environmental tobacco smoke. The 
studies by Manning, et al. (1989, 1991), did not include environmental tobacco smoke because the evidence at the time of their study was too fragmentary to make a reliable judgement. since the time of their study, both OSHA and EPA have issued reports with environmental tobacco smoke risk estimates bassed on this literature. Notwithstanding these agencies' willingness to issue such judgements, other critics continue to suggest that the linkages are not sufficiently strong or well-documented to warrant the same kind of treatment as, for example, the risks to the smokers themselves. The recent assessment of environmental tobacco smoke risks by Gravelle and zimmerman (1994) in their Congressional Research Service study concluded, for example, that evidence was still too inconclusive to warrant calculation of any external costs associated with environmental tobacco smoke exposures.

Having made these caveats, I will present estimates of the costs imposed by environmental tobacco smoke based on the EPA and oSHA studies. I will then adjust these estimates to account for factors such as the change in the tar level of cigarettes that were ignored in these government studies. Calculating these estimates in no way implies acceptance of their validity. As a consequence, I will review some of the most salient limitations of these studies in the course of presenting them. Readers who wish to make alternative judgments, such as setting these risks equal to zero, can utilize the results presented here to undertake the appropriate sensitivity tests. 
There are two broad classes of environmental tobacco smoke (ETS) risks -- lung cancer and heart disease. Most of the debate in the literature has been over the validity of the lung cancer risk estimates. Of the two classes of risk effects, these are the better established. However, as will be indicated below, even the lung cancer estimates are the object of substantial, legitimate controversy. The heart disease estimates have been regarded as being highly speculative by the authors of the heart disease studies as well as by the agencies employing these results. Because all parties have given less credence to the heart disease estimates, these estimates have not been the object of as much public discussion. However, since the heart disease mortality rates are considerably larger than those of lung cancer, it is important both to recognize their potential implications as well as the limitations associated with their estimation.

\section{Lung Cancer Risks}

The first class of ETS risks to be considered is that associated with lung cancer. The scientific evidence that led to the lung cancer risk assessments by EPA consisted of 11 studies of family members exposed to ETs. Of these studies only one showed statistically significant effects at the 10 percent confidence level, which is a less demanding statistical test than EPA traditionally applies. "Significant" results such as this may occur on a random basis. Despite the fact that only one of the studies yielded relationships that were statistically 
significant and the substantial lack of comparability among the eleven studies, which were undertaken with data adjusted in different ways and collected from the 1960s through 1988, EPA pooled the estimates to make an overall ETS risk assessment. Even based on EPA's risk estimates, the ETS risks are at least two orders of magnitude smaller than the risks to smokers themselves.

These estimates neglected a variety of fundamental aspects of the risk. They did not, for example, account for the change in the tar content or per smoker consumption of cigarettes over time. These adjustments will be made below, using the same weighting system of the studies adopted by EPA. Another principal drawback of the ETS studies is that they pertain to risks to other household members. Those exposed to public ETS will typically be exposed to lower concentrations of ETS as well as shorter durations of exposures than the family members of a smoker. To the extent that there is a no risk threshold, low levels of exposure to ETS may cause no risk whatsoever to the exposed population.

The character of the studies also is quite different from what economists might envision. There were, for example, no detailed multivariate controls to capture differences in demographic characteristics or location, though some studies did make a few primitve demographic adjustments. If smokers choose to live in highly polluted areas, and if they and their families get lung cancer because of their broader environmental exposures, 
this type of relationship would be captured in these studies and incorrectly attributed to ETS. Similarly, smokers will be more likely to be married to other smokers. Higher mortality rates from ETS may reflect smoking behavior of other family members rather than ETS. Intra-family correlations in exposure to risks and risk-taking propensities will tend to produce spurious correlations.

The nature of the research results is also difficult to interpret. One recent study "found no adverse effect of exposure to environmental tobacco smoke during adulthood, including exposure to a spouse who smoked." 21 whether the apparent ETS risk to children arises from exposure during pregnancy to a smoking mother or ETS exposure after birth is unclear.

In some instances, inconsistent research results have been treated in a way that reflects advocacy of an ETs-cancer link rather than a scientific assessment of causality. One 1992 study found that spouses of low and moderate smokers had a 30 percent lower probability of lung cancer, whereas spouses of heavier smokers had a 30 percent higher probability of lung cancer. ${ }^{22}$ Although the authors stress the latter finding, taken at face value their results imply an implausibly shaped dose-response relationship between ETS and cancer that is initially negative and then positive.

21 See Janerich, et al. (1990).

22 This example is drawn from Robert J. Barro, "Send Regulations Up in Smoke," Wall Street Journal, June 3, 1994. 
In making its estimate of the number of people exposed to ETS, EPA also understates the extent to which workers have already been prevented from being exposed to ETS, thus overstating the potential risk. Many workplaces have installed special smoking lounges and banned workplace smoking. EPit may underestimate the number of workers covered by bans since larger establishments are most likely to have bans or designated smoking areas ( 74 percent of firms with 750 or more employees versus 55 percent with 50-99 employees). ${ }^{23}$ EPA, however, did not adjust for workplace size. The EPA estimates recognize only the efficacy of the 20 percent of the smoking lounges that meet the strict standards proposed recent legislation (HR3434). However, if the other lounges have some partial efficacy, than one would want to take this influence into account. As a result, I will also explore the sensitivity of the results to the assumption one makes about the prevalence of bans and effective smoking lounges. A final caveat that will be noted before considering the risk estimates is that there is an inconsistency between the EPA and OSHA risk estimates. ${ }^{24}$ EPA estimates that each year 2,200 people die from lung cancer due to ETS exposures. When analyzing deaths in the workplace, OSHA estimates that 140-722 deaths per year arise from workplace exposures. In this case, OSHA did not

\footnotetext{
${ }^{23}$ See EPA (1994), Exhibit 7-1.

24 The EPA estimates appear on p.12 of EPA (1994), and the OSHA estimates appear on p.16011 of the Federal Reqister. The OSHA figures pertain to the average number of lung cancers over the next 45 years whereas the EPA estimates pertain to the current risk estimates.
} 
follow EPA's procedure of pooling the results of the risk studies irrespective of their statistical significance. These numbers can be linked, as EPA estimates that 82 percent of non-home exposures occur at work. If one were to apply this workplace exposure estimate to the OSHA mortality estimate, one obtains an OSHA-based risk estimate of 171-880 lung cancer deaths from nonhome exposures. Thus, there is considerable inconsistency within the Federal Government in the assessment of the lung cancer risk levels.

To obtain the estimate of the value of statistical lives, I utilized the $\$ 5$ million value per statistical life from viscusi (1992a, 1993). This value is the midpoint estimate of the estimated value of life range based on wage-risk tradeoffs. This value of life is pertinent for a worker with an average life expectancy of 36.5 years that will be lost because of an injury. In contrast, an individual who contracts lung cancer because of ETS exposures will incur much less of a loss in life expectancy than would a worker suffering an acute injury. The average life expectancy loss for a victim of a smoking-related disease is 12.1 years. ${ }^{25}$ For concreteness, I have used the discounted estimated life expectancy loss for smokers in making the calculation. Thus, the pertinent value of $l$ ife is $\$ 5$ million, multiplied by the ratio of the discounted expected life years lost from smoking divided by the discounted expected number of life years lost by a worker. One should also, however, adjust this lost value for the

${ }^{25}$ See Center for Disease Control (1993). 
fact that it is deferred. People exposed to environmental tobacco smoke are not killed instantaneously so that there must be appropriate recognition of the time lags involved in making these assessments.

Table 6 provides three sets of estimates. Panel 1 in the table provides estimates based on EPA risk assessments, and the bottom panel provides estimates derived by extrapolating the OSHA ETS risk estimates for the workplace. Within the Panel 1, the bottom two sections adjust for the discrepancy between EPA's estimate of the number of people at risk and the estimated number of people at risk derived from the OSHA study. All risk assessments in Panel 1 are based on EPA estimates. In contrast, Panel 2 in Table 6 utilizes both the OSHA risk estimates and estimates of the population at risk based on OSHA's assessment. For each of these estimates, the columns indicate the differing assumptions that have been made with respect to the tar level of cigarettes. The first column pertains to that in which the ETS studies correctly capture the tar levels. The next two columns reflect the estimates for which there is a 20 year moving average that determines the risk level and for which it is the 20 year lagged point estimate that determines the risk. The final two columns present estimates for the 30 year moving average and 30 year lag case.

The first two rows in the table indicate the total number of lung cancer deaths and the associated costs attributable to ETS using the EPA assumptions in which there is no tar adjustment. 
Table 6

\section{Lung Cancer Deaths Caused by ETS Outside the Home.}

Tar Level Assumption Linking RIsk to Exposures

20 yr.

$30 \mathrm{yr}$.

Moving 20 yr. Point Moving 30 yr. Point

EPA-Based Estimates

Number of Deaths

Averag

Estimate

Average

Estumate

Cost ( $\$$ billions)

No Lag Average

With $50 \%$ Tar Adjustment:

Number of Deaths

1,694

1,694

1,694

1,694

1,694

$\$ 2.80$

$\$ 1.53$

50.83

51.05

$\$ 0.45$

Cost ( $\$$ billions)

1,389

1,285

1,279

1,247

1,220

With 100\% Tar Adjustment:

Number of Deaths

$\$ 2.29$

$\$ 1.16$

sา.63

so 77

$\$ 0.32$

Cost ( 5 Billions)

1,171

864

696

748

525

OSHA-Based Estimate - Lower Bound With 50\% Tar Adjustment:

Number of Deaths

Cost ( $\$$ billions)

With 100\% Tar Adjustment:

Number of Deaths

$$
444
$$

$\$ 0.78$

$\$ 0.34$

$\$ 0.46$

$\$ 0.14$

Cost (\$ Billions)

OSHA-Based Estimate - Upper Bound With $50 \%$ Tar Adjus tment:

$\begin{array}{lrrrrr}\text { Number of Deaths } & 1.150 & 1,296 & 1,059 & 1,032 & 1,010 \\ \text { Cost ( } \$ \text { billions) } & \$ 1.89 & \$ 1.17 & \$ 0.52 & \$ 0.64 & \$ 0.27 \\ \text { With 100\% Tar Adjustment: } & & & & & \\ \text { Number of Deaths } & 970 & 872 & 577 & 620 & 434 \\ \text { Cost (\$ Billions) } & \$ 1.60 & \$ 0.79 & \$ 0.28 & \$ 0.39 & \$ 0.12\end{array}$

EPA number at risk $=69.1$ million (EPA 92)

EPA number at risk with $23 \%$ restrictions $=53.2$ million

OSHA number at risk $=14.0$ to 36.1 million (OSHA $94-p .16007$ )

\begin{tabular}{|c|c|c|c|c|c|}
\hline & No Lag & $\begin{array}{l}20 \mathrm{yr} . \\
\text { Moving } \\
\text { Average }\end{array}$ & $\begin{array}{l}20 \text { yr. Polnt } \\
\text { Estumate }\end{array}$ & $\begin{array}{l}30 \text { yr. } \\
\text { Moving } \\
\text { Average }\end{array}$ & $\begin{array}{c}30 \text { yr. Polnt } \\
\text { Estumate }\end{array}$ \\
\hline $\begin{array}{l}\text { Lower Bound } \\
\text { Number of Deaths }\end{array}$ & 171 & 171 & 171 & 171 & 171 \\
\hline $\begin{array}{l}\text { Cost ( } \$ \text { billions) } \\
\text { Upper Bound }\end{array}$ & $\$ 0.28$ & $\$ 0.15$ & 50.08 & $\$ 0.11$ & $\$ 0.05$ \\
\hline Number of Deaths & 880 & 880 & 880 & 880 & 880 \\
\hline Cost ( $\$$ Billions) & $\$ 1.46$ & $\$ 0.79$ & $\$ 0.43$ & $\$ 0.55$ & 50.23 \\
\hline
\end{tabular}

Note: EPA (1994 - p.12) says $18 \%$ of ETS exposure occurs at the worksite and another $4 \%$ occurs at other covered locations outside the home. This implies that $82 \%$ of non-home exposure occurs at the worksite. These data are used to extrapolate the OSHA workplace risk estimates to the entire population.

For reference purposes, the lung cancer estimates embodied in the OSHA estimates appear above.

See appendix for how tar adjustment factors are derived for the differing assumptions regarding latency periods. 
The mortality estimate is a constant value of 1,694 in all cases, but the monetized value of the lives lost differs because the time frame affects the discounted value of the these losses, where a discount rate of three percent is used throughout. The next set of rows indicates the mortality costs if one makes an adjustment for half of the reduction in tar levels and 100 percent of the reduction. If nonsmokers benefit to the same extent as do smokers from the decreased tar levels, then the 100 percent estimates are pertinent. If, however, they benef:tted from only 50 percent of the reduction in tar, only half the change in tar levels is relevant. To the extent that the improvements in tar are achieved through devices such as filters rather than changes in the composition of cigarettes, there would tend to be less than a 100 percent effect.

For purposes of illustration, consider the middle 20 year point estimate set of results. The original EPA estimate of 1,694 deaths is reduced to 1,279 if half of the change in tar levels is accounted for and 696 of the entirety of the tar change is recognized. The value of the mortality costs changes similarly, as it decreases from $\$ 0.88$ billion in the base EPA case to $\$ 0.67$ billion in the 50 percent reduction case, and $\$ 0.36$ billion in the 100 percent reduction case.

If instead one utilizes the EPA risk estimates in conjunction with the OSHA number at risk, one obtains considerably lower estimates of the mortality cost. For the 100 percent tar adjustment case, estimates based on the low end of 
the OSHA risk assessment are 223 deaths and a monetary cost of \$0.12 billion, with the high estimate being 577 deaths and $\$ 0.30$ billion.

Table 7 adjusts the outside the home ETS lung cancer estimates assuming that current smoking restrictions are 50 percent effective rather than EPA's assumption that restrictions are 23 percent effective. ${ }^{26}$ If these adjustments are made, then one obtains estimates in Table 7 which are roughly two-thirds the size of those in the top Panel 1 of Table $6 .^{27}$ The OSHA-based estimates in Table 7 reflect the population adjustment not OSHA's risk value adjustment. If additional restrictions on smoking in the workplace are enacted, as would be the case if OSHA enacts its proposed regulation banning workplace smoking except in designated areas, then these estimates would of course be dramatically reduced even further.

In much the same manner, one can calculate the lung cancer deaths caused by ETS inside the home. Table 8 provides these estimates. There are no OSHA-based estimates for this table since OSHA did not address risks within the home. For the EPAbased risk estimates there will be 800 deaths per year within the home. Making the 50 percent tar adjustment reduces these estimates by an average of about one-fourth, and making the 100

${ }^{26}$ U.S. Environmental Protection Agency (1994), p. 28. Also see notes to Table 4 .

27 Panel 2 in Table 6 is not adjusted since osha did not indicate its smoking restriction for the underlying risk estimates. 


\title{
Table 7
}

\section{Lung Cancer Deaths Caused by ETS Outside the Home With an Assumption of $50 \%$ Effectiveness of Current Restrictions}

\author{
Number of Deaths and Discounted Cost of Deaths (Billions of Dollars) \\ $20 \mathrm{yr}$. \\ $30 \mathrm{yr}$. \\ Moving 20 yr. Point Moving
}

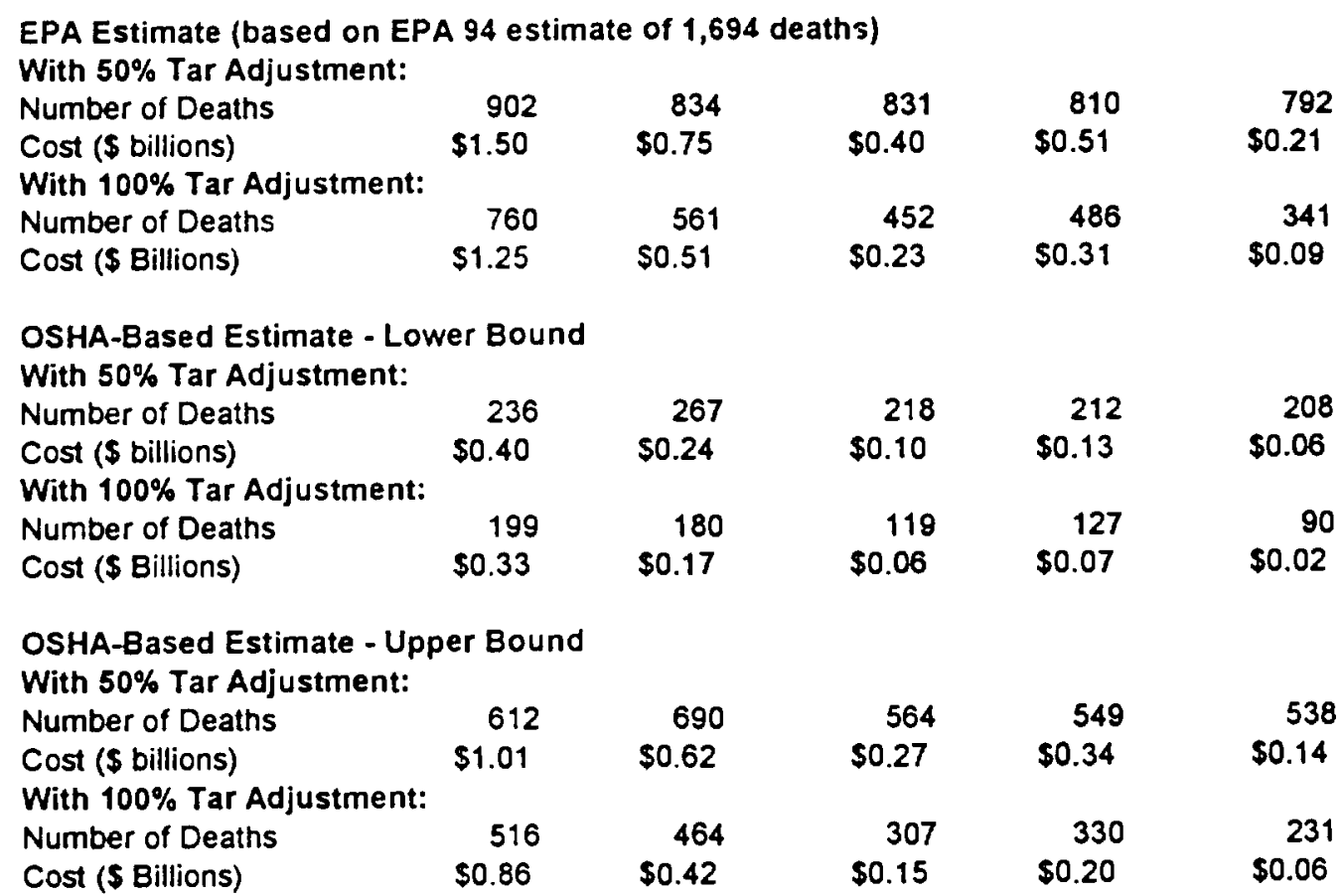

See appendix for how tar adjustment factors are derived for the differing assumptions regarding latency periods. 


\section{Table 7 continued}

Note: The first two panels of Table 6 assumed that 23\% of worksites (EPA 1994) are currently subject to restrictions comparable to those proposed by the EPA. Table 7 incorporates evidence that the EPA underestimated the number of persons subject to these restrictions and assumes that $50 \%$ of workplaces are currently covered. The reasoning for this is as follows. First, the EPA data suggest that $59 \%$ of worksites with more than 50 employees are subject to smoking bans or have effective smoking lounges. This is used as evidence that $59 \%$ of persons working at these sites are subject to these restrictions. This conclusion is not valid, however, because there is a direct correlation between worksite size and smoking restrictions (with $74 \%$ restrictions for the largest worksites). Since there are more persons working at these larger worksites (and, thus, subject to the greater restriction), one would expect that more than 598 of the persons in this category would be subject to restrictions.

second, the EPA assumes that $10 \%$ of all worksites with fewer than 50 persons are subject to similar restrictions. This estimate appears to be arbitrary given that there is no available data for these firms. A reasonable extrapolation of rates from worksites with greater than 50 persons would lead to a much higher estimate.

Third, the EPA only includes smoking lounges that would meet the standards of their proposed rule. This is only 208 of all smoking lounges. The other $80 \%$ also afford nonsmokers some protection, which is not recognized by EPA.

Finaliy, the data used is from 1992, but the policy would not be implemented until 1995 at the eariiest. Normally this discrepancy would be considered insignificant. In this case, however, there is already a strong trend toward private (and local public) restriction. Restrictive smoking policies increased from $27 \%$ in 1985 to 598 in 1992 .

Given the magnitude of the errors in the EPA analysis, $50 \%$ restrictions may be a conservative estimate. 


\title{
Table 8
}

\section{Lung Cancer Deaths Caused by ETS Inside the Home.}

\author{
Number of Deaths and Discounted Cost of Deaths (Billions of Drillars) \\ $20 \mathrm{yr}$. \\ 30 yr. \\ Moving 20 yr. Point Moving 30 yr. Point \\ No Lag Average Estimate Average Estimate
}

EPA-Based Estimate

Number of Deaths

800

800

800

800

800

Cost ( $\$$ billions:

$\$ 1.32$

$\$ 0.72$

$\$ 0.39$

$\$ 0.50$

$\$ 0.21$

With 50\% Tar Adjustment:

Number of Deaths

656

607

604

589

576

Cost ( $\$$ billions)

With $100 \%$ Tar Adjustment:

$\$ 1.08$

$\$ 0.55$

$\$ 0.30$

$\$ 0.36$

$\$ 0.15$

Number of Deaths

553

408

329

353

\$0.91

$\$ 0.37$

\$0.16

$\$ 0.22$

248

$\$ 0.06$

The base figure is from the U.S. EPA (1994).

See the appendix for how tar adjustment factors are derived for the differing assumptions regarding latency periods. 
percent tar adjustment reduces the estimates by an average of about one-half. It should be emphasized that including any lung cancer death risk estimate inside the home within an externality assessment is problematic since these costs may be internalized by the smoker who takes into account the well-being of family members in making the smoking decision.

\section{Heart Disease}

The overall mortality costs associated with the ETS-heart disease linkage are even greater. EPA estimates that from 8,76017,520 deaths per year from heart disease are due to ETS exposures outside the home.

Although these estimates are higher than those for lung cancer, they are based on much weaker scientific evidence. Indeed, the recent study by steenland (1992) that provides the scientific basis for EPA's estimates includes a myriad of caveats and cautionary notes that should make one reluctant to attach much precision to these estimates. ${ }^{28}$ To deal with what the

${ }^{28}$ In particular, steenland (1992) makes the following observations: "While the lung cancer risk among never-smokers exposed to ETS is well established, a possible risk of heart disease due to ETS is more controversial. (p. 94) ... Environmental tobacco smoke is difficult to measure directly. (p. 94) ... The relative contribution of ETS exposure at work to total exposure is not well known. (p. 94) ... The principal weaknesses in the epidemiologic evidence to date have been the indirect methods of assessing exposure (via spousal smoking) and the lack of data on exposures to ETS outside the home. (p. 95) ... Also, there are many risk factors for heart disease, and it is difficult to control well for all of them. Another problem with the epidemiologic data is the seemingly large effect that ETS has on heart disease compared with the effect of mainstream smoking. (p. 95) ... They showed no excess of lung cancer, and cross-sectional smoking data revealed smoking habits similar to the U.S. referent population. Hence, increased cigarette smoking 
author termed "considerable uncertainty" regarding the results, EPA simply scaled down the mortality estimates. It should also be noted that although EPA adopted the steenland (1992) findings, it did not adopt steenland's result that 55 percent of heart disease deaths are due to non-house exposures, but instead adopted a 73 percent assumption, which would lead to a higher estimated public externality.

The EPA estimates of heart disease also suffer from the same classes of deficiencies as did the lung cancer risk estimates. In particular, they did not take into account the lag time between exposure and the onset of disease, and they abstracted from changes in the tar level and composition of cigarettes. Table 9 summarizes the heart disease mortality estimates that will occur outside the home. In each case, low and high estimates based on the EPA assumptions are presented, and the table also includes low and high estimates based on OSHA's estimates of the mortality costs of ETS. The annual death count in every instance is much higher than the lung cancer mortality rate. If one uses the non-home exposure amount advocated by

\footnotetext{
was unlikely to explain the excess heart disease risk. (p. 96) ... A number of assumptions are involved in estimating the heart disease mortality due to ETS, adding an unfortunate level of uncertainty. The most important assumption is that the relative risks for ETS and heart disease, derived from the epidemiologic evidence, are reasonable accurate. The epidemiologic results may be questioned, given the inherent uncertainties of any epidemiologic study. ( $p$. 98) ... Considerable uncertainty is involved in extrapolating from the epidemiologic data, which consider the relative risks for never-smokers living with smokers, to estimating relative risks for those exposed to Ers (anywhere) vs those truly not exposed (anywhere). (p. 98)"
} 
Table 9

Mortality Costs Outside the Home Due to Heart Disease

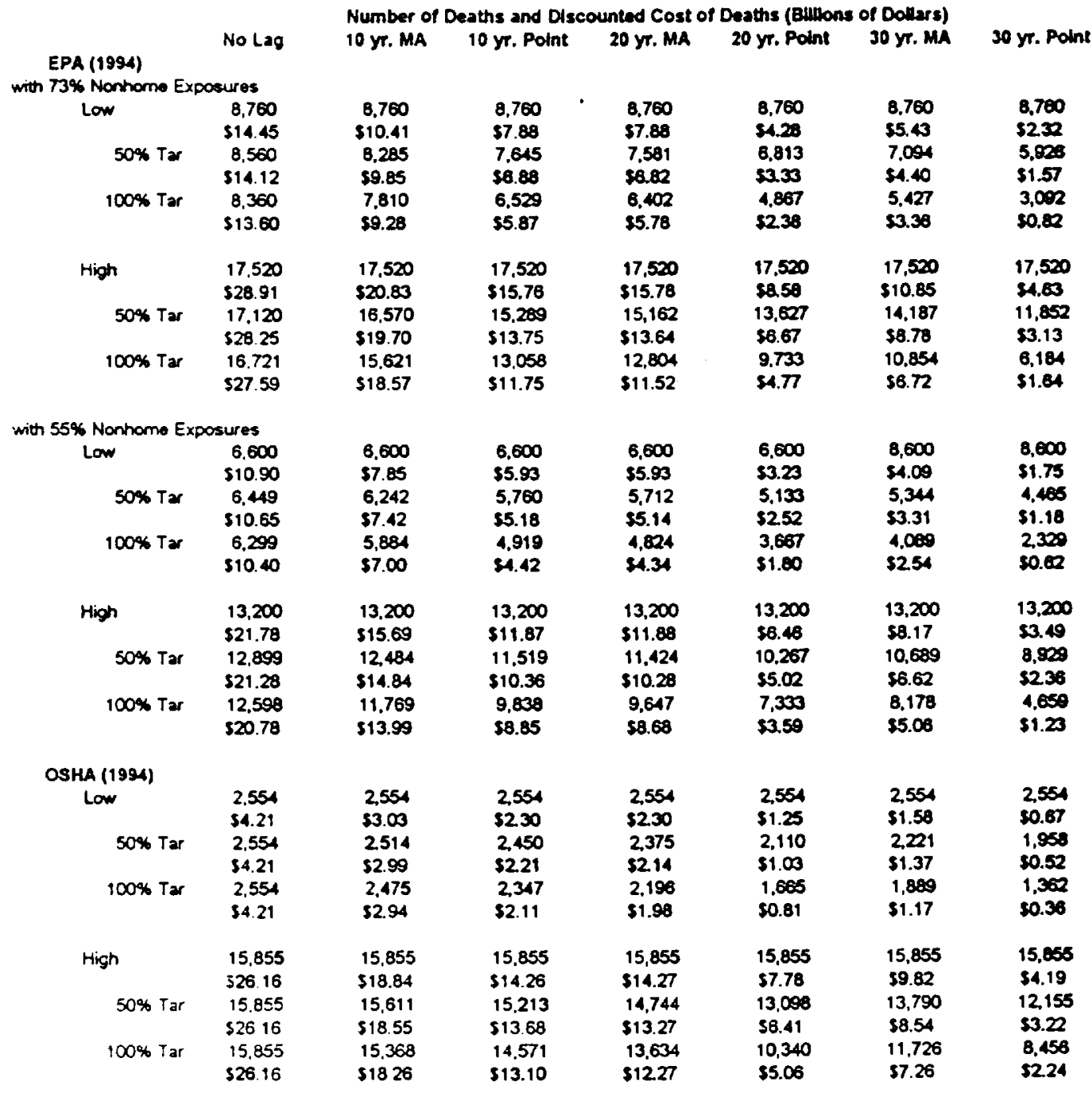




\section{Table 9 continued}

Note: The OSHA estimates are based on a 45 year average. OSHA figures from p.16011, Federal Register, April 5, 1994. The OSHA estimates were adjusted to account for EPA's assumption that 82 of all exposures are at the worksites. See discussion of Table 6 for further details. The EPA tar adjustment is 1 imited to base year of 1988, which is the year of the heart disease study by Wells (1988) used by EPA. The OSHA tar adjustmerits are based on 1994 tar levels with an assumption that OSHA rist: levels are contemporaneous. See appendix for how tar adjustment factors are derived for differing assumptions regarding latency periods. The no tar, $50 \%$ tar and $100 \%$ tar figures are derived by dividing the base number of deaths (and the cost of deaths) by the modified tar adjustment figures. The modification for no tar and $50 \%$ tar are best illustrated through an example. A $100 \%$ tar adjustment figure of 1.5 would only be 1.25 under the $50 \%$ assumption and 1 under a no tar assumption.

The $73 \%$ nonhome exposure case is taken from EPA 1994. The 55 nonhome exposure case is from steenland (1992). 
Steenland (1992) of 55 percent rather than the 73 percent estimate utilized by EPA, one reduces the mortality estimate and associated costs. Both cases appear in Table 9 .

The discounted cost associated with these deaths has a value ranging from $\$ 4.6$ billion to $\$ 9.2$ billion in the 20 year point estimate case where these estimates are based on the assumption that the extent of life lost due to heart disease from ETS exposures is the same as the life expectancy loss attributable to smoking overall. If one adopts a 100 percent tar adjustment, there estimates decline to $\$ 2.5$ billion $-\$ 5.1$ billion. The other columns in Table 9 represent other tar lag situations, ranging from no lag between EPA studies and tar levels, to the case in which there is a 30 year lag time. The importance of these lags is apparent, as the 30 year point estimates of the costs are considerably below the values in the situation in which there is no lag.

Table 10 presents analogous findings for heart disease deaths caused by ETS inside the home. Results appear assuming 27 percent of exposures are inside the home (EPA's assumption and 45 percent (steenland estimate). These mortality amounts are also substantial, as the death count range even in the lowest scenario presented is 3,240 annual deaths. Even with a 30 year lag before these deaths occur, the mortality costs are $\$ 1.25$ billion if one makes no tar adjustment. As with the public ETS risks, tar adjustments substantially decrease these values.

Table 11 summarizes the passive smoking costs evaluated at a 


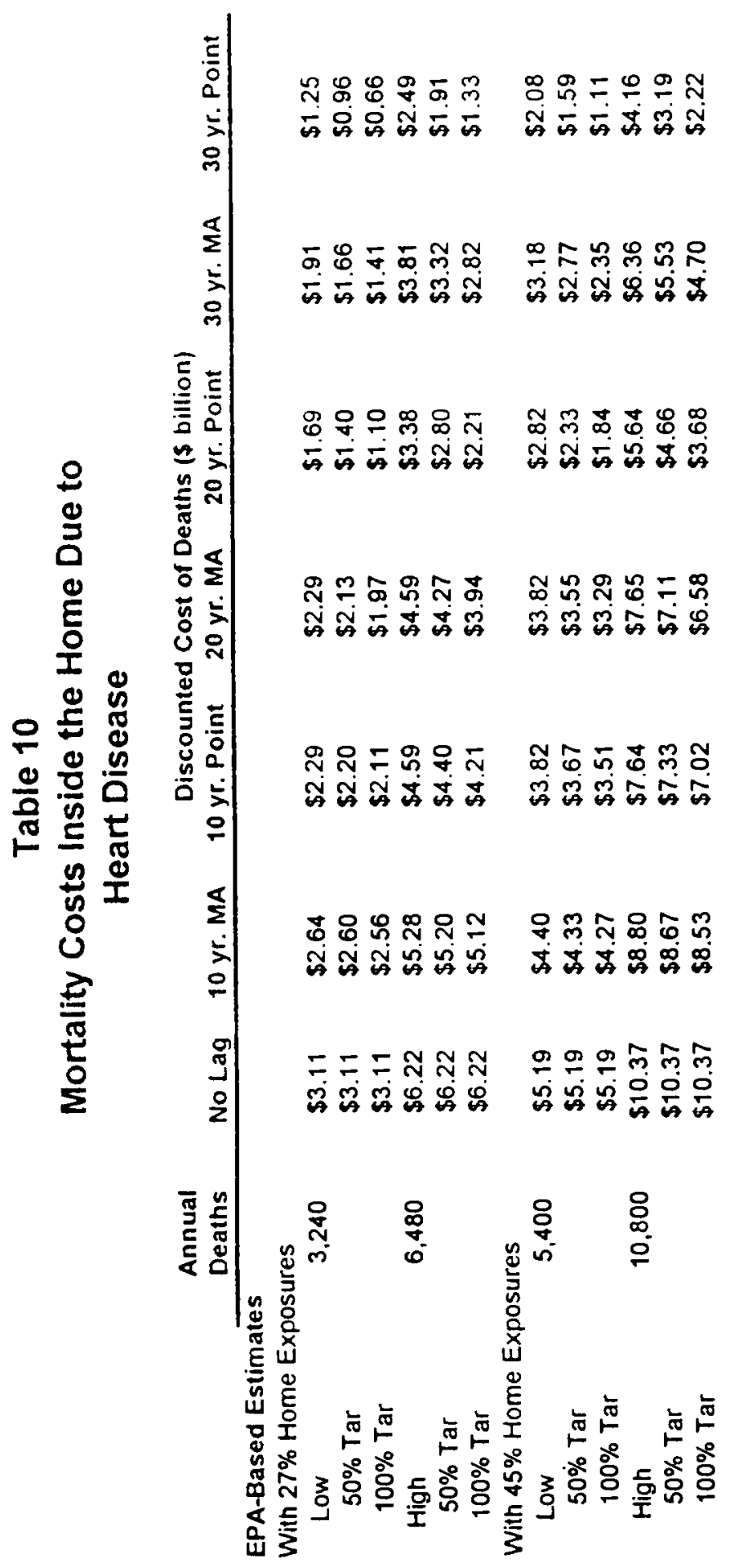




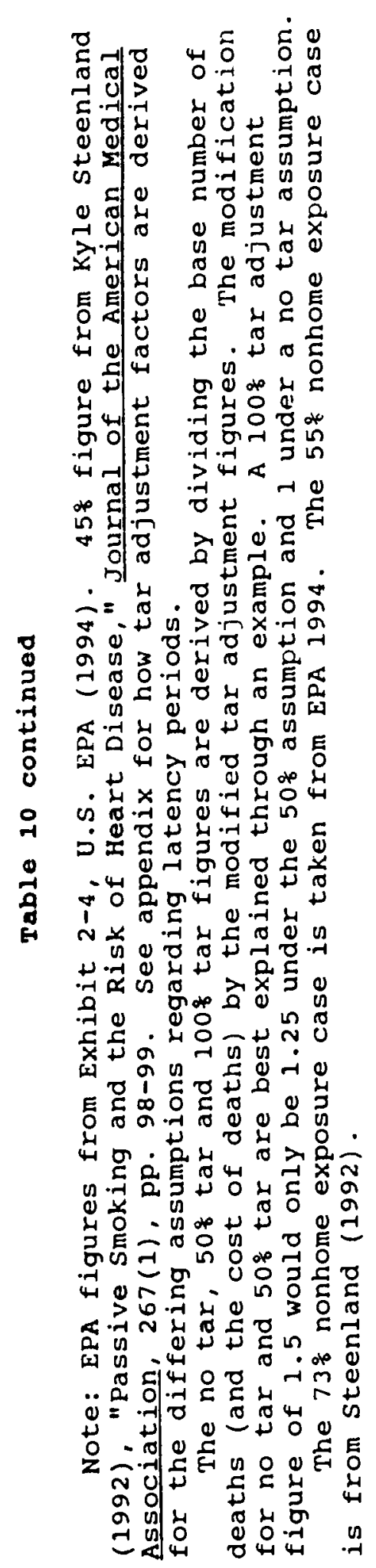




\section{Table 11 \\ Total Annual Social Costs}

\section{Insurance Externalities (\$ bllilons),}

assuming $3 \%$ discount rate

No Tar Adjustment

No Lag 20 yr. MA 20 yr. point 30 yr. MA 30 yr. point

Smoker's insurance Externalities

ETS Externalities Insurance

$$
\begin{array}{r}
\text { Low } \\
\text { Median } \\
\text { High }
\end{array}
$$

Tar Adjusted

Smoker's Insurance Externalities

ETS Externalities Insurance

Low
Median
High

$(\$ 7.43)$

$(\$ 7.43)$

$(\$ 7.43)$

(\$7.43)

(\$7.43)

(\$0.25)

(\$0.36)

(\$0.46)

$(\$ 0.25)$
$(\$ 0.36)$
$(\$ 0.46)$

(\$0.25)

(\$0.36)

(\$0.46)

(\$0.25)

(\$0.36)

(\$0.46)

(\$0.25)

(\$0.36)

(\$0.46)

$$
\text { (\$7.79) }
$$

(\$6.74)

(\$6.26)

(\$6.32)

$(\$ 5.65)$

$\begin{array}{lllll}(\$ 0.26) & (\$ 0.23) & (\$ 0.21) & (\$ 0.21) & (\$ 0.19) \\ (\$ 0.37) & (\$ 0.32) & (\$ 0.30) & (\$ 0.30) & (\$ 0.27) \\ (\$ 0.48) & (\$ 0.42) & (\$ 0.39) & (\$ 0.39) & (\$ 0.35)\end{array}$

\begin{tabular}{|c|c|c|c|c|c|c|}
\hline (non-home) & Low & $\$ 0.28$ & $\$ 0.15$ & $\$ 0.06$ & $\$ 0.11$ & $\begin{array}{l}\$ 0.02 \\
\$ 0.12\end{array}$ \\
\hline & $\begin{array}{r}\text { Median } \\
\text { Hiah }\end{array}$ & $\begin{array}{l}\$ 1.25 \\
\$ 2.80\end{array}$ & $\$ 0.62$ & $\begin{array}{l}\$ 0.27 \\
\$ 0.83\end{array}$ & $\begin{array}{l}\$ 0.34 \\
\$ 105\end{array}$ & $\begin{array}{l}\$ 0.12 \\
\$ 0.45\end{array}$ \\
\hline
\end{tabular}

ETS Mortality Smoking Costs

No Lag 20 yr.MA 20 yr. point 30 yr. MA 30 yr. point

Lung Cancer

\begin{tabular}{|c|c|c|c|c|}
\hline & Fire Death & & & \\
\hline No Lag & 20 yr. MA & 20 yr. point & 30 yr. MA & $\begin{array}{l}30 \text { yr. point } \\
\text { s0.03 }\end{array}$ \\
\hline
\end{tabular}

Heart Disease

$\begin{array}{rrrrrrr}\text { (non-home) } & \text { Low } & \$ 4.21 & \$ 1.98 & \$ 0.81 & \$ 1.17 & \$ 0.36 \\ \text { Median } & \$ 12.10 & \$ 5.88 & \$ 3.20 & \$ 4.05 & \$ 1.73 \\ \text { High } & \$ 27.59 & \$ 15.76 & \$ 8.58 & \$ 10.85 & \$ 4.63\end{array}$

(non-residential) 
Note: Smoker's insurance externalities are taken from Tables 4 and 5, and are multiplied by the number of packs consumed in the U.S. (The Tobacco Institute, 1994). ETS insurance externalities are found by dividing ETS deaths by total smoker's deaths due to smoking (CDC 1993) and multiplying this fraction with smoker's insurance externalities. Costs of ETS deaths from lung cancer are the low, median, and high figures from Tables 6 and 7 . Costs of heart disease are the low, median, and high numbers from Table 9. The low, median and high numbers for each category (no lag, 20 year MA, etc.) are found by visual inspection except where the median is an average of the two closest. figures. For example, the no lag, heart disease numbers from Table 9 would be: low $=\$ 4.21$, median $=\$ 17.62$ $((14.45+20.78) / 2)$, and $\mathrm{high}=\$ 28.91$. Non-residential fire deaths are for 1990 (FEMA 1993) and are valued at $\$ 5$ million dollars per death. 
3 percent discount rate. These are the ETS values that will be used in calculating the total externality costs of cigarettes. These categories of costs are considered: insurance externalities, ETS mortality costs, and fire-related mortality. The inside-the-home heart disease death estimates are excluded for two reasons. First, deaths inside the home may well be internalized by the smoker and consequently are not externalities. Second, as in the case of the other heart disease estimates, the underlying scientific basis for these estimates is extremely iragile and highly speculative. The low and high estimates are quite disparate, so the assumptions one adopts are consequential. For the median estimates and a 20 year point estimate for the tar adjustment, the net ETS cost is 27 cents per pack, virtually all of which is due to heart disease costs.

Table 11 also adds the costs of nonresidential fire-related mortality. These calculations assumed a value of life of $\$ 5$ million.

8. Conclusion: The Net Externality Costs of Smoking At the current time, smokers pay an average of $\$ 0.53$ per pack in cigarette taxes. If our objective is to set an appropriate tax level to reflect the externalities generated by cigarettes, the question then becomes whether this tax amount is sufficient to address the externality costs imposed.

These costs consist of several potential elements. The first of these, the externalities to the smoker's future self appear to be unimportant.. Very few smokers underestimate the 
hazards associated with smoking, and indeed overall smokers overassess the risks of smoking. To the extent that smokers also internalize the ETS risks to household members, this effert would be captured as well in these private decisions.

The focal point of the externality cost debate has not been losses to the smokers' future selves but on the health insirance and related costs associated with smoking. A comprehensive assessment of these costs suggests that on balance smokers do not cost society resources because of their smoking activities, but rather save society money. Evidence presented in section 6 indicates that at reasonable rates of discount the cost sivings that results because of the premature deaths of smokers through their lower social security and pension costs will more than compensate for the added costs imposed by smokers, chiefly through higher health insurance costs. Thus, not only is there not a rationale for imposing a tax due to these insurance-related externalities, but rather on balance there is a net cost savings to society even excluding consideration of the current cigarette taxes paid by smokers.

The principal externality cost component that might provide the impetus for a cigarette tax consists of ETS costs. Environmental tobacco smoke, however, is now the target of a wide-range of explicit regulatory proposals that would limit public exposures to ETS. Legislation before Congress would ban smoking in public places. The Occupational Safety and Health Administration has proposed a regulation that would ban smoking 
in the workplace except in situations where a designated smoking are meeting stringent ventilation conditions was provided. If these measures are enacted, it would not be appropriate to consider the current levels of externals cost of ETS in setting the appropriate tax level because the public externalities would have been addressed by an alternative policy tool, direct regulation.

If, however, we proceed under the assumption that these measures will not be enacted, then the costs associated with ETS are potentially very large, if one accepts the very imprecise scientific risk judgments of EPA and OSHA. If one takes these types of estimates at face value and incorporates them in a net tally of the combined externalities associated with smoking, including the cost of ETS as well as all the insurance-related costs, one obtains the net cost figures indicated in Table $12 .^{20}$ The top panel of Table 12 indicates the cost with no tar adjustments and the bottom panel indicates the tar-adjusted cost. Based on the 30 year point estimates and the median risk

${ }^{29}$ The figures in Table 12 are calculated as the sum of insurance externalities, passive smoking costs, passive smoking insurance externalities, and nonresidential fire deaths. Insurance externalities are computed as the estimates from Table 5 times the number of packs sold in 1993 (The Tobacco Institute, 1993, p.6). Passive smoking costs are assessed as the low, median, and high numbers from Tables 6,7 (lung cancer), and 9 (heart disease). Passive smoking insurance externalities are estimated as the insurance externalities figure times the number of deaths due to passive smoking divided by the total number of smoking attributable deaths (CDC 1994). The value of nonresidential fire deaths is calculated as the number of nonresidential fire deaths in 1990 (Federal Emergency Management Agency, 1993) times the unadjusted value of life figure. 


\section{Table 12 Summary of External Costs of Smoking}

No Tar Adjustment

\begin{tabular}{|c|c|c|c|c|c|}
\hline & & Total N & $\begin{array}{l}\text { Vet Smokir } \\
\text { (billions of dolla }\end{array}$ & $\begin{array}{l}\text { ig Costs } \\
\text { ars) }\end{array}$ & \\
\hline & No Lag & 20 yr. MA & 20 yr. point & 30 yr. MA & 30 yr. point \\
\hline $\begin{array}{r}\text { Low } \\
\text { ledian } \\
\text { High }\end{array}$ & $\begin{array}{r}(\$ 3.16) \\
\$ 5.60 \\
\$ 22.53\end{array}$ & $\begin{array}{c}(\$ 5.52) \\
(\$ 1.25) \\
\$ 9.43\end{array}$ & $\begin{array}{c}(\$ 6.78) \\
(\$ 4.28) \\
\$ 1.55\end{array}$ & $\begin{array}{c}(\$ 5.56) \\
(\$ 1.53) \\
\$ 8.95\end{array}$ & $\begin{array}{l}(\$ 8.82) \\
(\$ 4.43) \\
\$ 1.47\end{array}$ \\
\hline & No Lag & $\begin{array}{l}\text { Exter } \\
20 \mathrm{yr} \text {. MA } \\
\end{array}$ & $\begin{array}{l}\text { rnal Cost pe } \\
20 \mathrm{yr} \text {. point }\end{array}$ & $\begin{array}{l}\text { Pack Pa } \\
30 \text { yr. MA }\end{array}$ & $30 \mathrm{yr}$. point \\
\hline $\begin{array}{r}\text { Low } \\
\text { Median } \\
\text { High }\end{array}$ & $\begin{array}{c}(\$ 0.13) \\
\$ 0.23 \\
\$ 0.92\end{array}$ & $\begin{array}{c}(\$ 0.22) \\
(\$ 0.05) \\
\$ 0.38\end{array}$ & $\begin{array}{c}(\$ 0.28) \\
(\$ 0.17) \\
\$ 0.06\end{array}$ & $\begin{array}{c}(\$ 0.23) \\
(\$ 0.06) \\
\$ 0.36\end{array}$ & $\begin{array}{c}(\$ 0.28) \\
(\$ 0.18) \\
\$ 0.05\end{array}$ \\
\hline
\end{tabular}

Tar Adjusted

Total Net Smoking Costs

(billions of dollars)

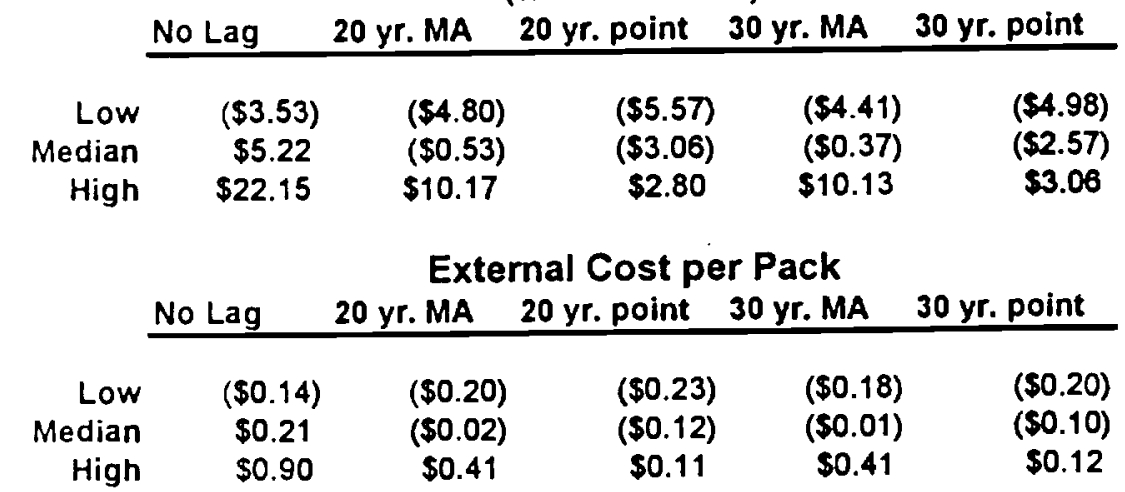

This table is derived by summing the costs found in table 11. Cost per pack is found by dividing total cost by the number of packs sold in the U.S. (The Tobaccos Institute, 1993) p. 6. 
assumptions, without a tar adjustment smokers on balance save society $\$ 0.14$ per pack even including ETS costs. In the taradjusted case smoking is a break-even proposition. Even the worst case scenario shown in the table in which there is no lag between smoking and the observed effects yields as a high estimate in the no tar adjustment case a value of $\$ 0.43$ per pack, which is an amount below current cigarette tax levels. As a consequence cigarette taxes already exceed the level of the estimated externalities.

It should be emphasized that these calculations were extremely conservative in that they included the very highly speculative ETS estimates. The high end of the range in effect takes the EPA estimates of the ETS risks at face value. Indeed, all the estimates presented here recognized a substantial ETS component even though one might have reasonably set these costs equal to zero, as in all previous smoking externality studies. These risks are highly debated and uncertain in the case of the lung cancer-ETS risk, and the evidence for the heart disease-ETS risk is at such a preliminary stage that the risk estimates border on being conjecture. However, even if we were to accept the highly uncertain risk estimates that have been put forth, the overall conclusion with respect to need for a higher cigarette tax is not affected. Although consideration of the ETS effects leads to a substantial shift in the externality cost estimates from all previous studies of this issue, overall cigarette taxes exceed the associated externalities. 
Appendix

The basic building block for the insurance-related externality cost estimates presented in section 6 consisted of the results reported in chapter 4 of Manning, et. al. (1991). see, in particular, Table 4-15. This study provided a comprehensive assessment of the external cost of smoking ky using the Health Insurance Experiment (HIE) Data and the National Health Interview survey (NHIS) data. In their study, the authors attempted to avoid contaminating the smoking estimates by purging the data of systematic differences between smokers and nonsmokers other than their smoking status. In doing this they created a "non-smoking smoker" stylized individual for use in their analyses. The procedure to be described here does not alter the fundamental structure of their assessment, but instead undertakes a large number of revisions in their estimates, most of which were price-related but some of which pertain to more fundamental considerations such as the adjustments for tar levels in cigarettes and per capita cigarette consumption. For ease of reference, these amendments of their analysis are distinguished by topic below.

\section{Medical Care}

In the case of medical care expenses for those under age 65 , the adjustment figure used is the real rate of medical cost increase since the period of their data. For this age range, the Manning, et al. (1991) data is taken from the HIE (1975) so the pertinent adjustment factor to bring the costs to 1993 dollars is 
1.585 (medical cost index taken from statistical Abstract of the United States, 1993 and World Almanac and Book of Facts, 1994). For individuals age 65 and over the data in Manning et.al. (1991) is from the NHIS (1983), leading to an adjustment factor calculated similarly to that for those under 65 of 1.3922 . sick Leave

Manning, et al. (1991) computed the sick leave costs using data in NHIE and NHIS. Manning, et al. used HIE for men under 65 years of age, while they used NHIs for men 65 and older. All the data for women was taken from NHIS, where NHIS data was used in conjunction with 1985 CPS data to determine individual wage rates. Manning, et al. assumed that 38 percent of the work loss was covered by sick leave.

Based on the information included in Appendix $G$ of Manning, et al. (1992), 97 percent of the earnings for men occur before age 65. As a result, 97 percent of men's earnings levels were updated from 1975 and three percent were updated from 1985, while 100 percent of the women's earnings were updated from the year 1985 .

To adjust the sick leave figures, the employment cost index, as reported in Employment Cost Indexes, 1975-1992, Bureau of Labor Statistics, U.S. Department of Labor, 1993, p. 21 was used. After obtaining the estimates for women and men, data from the Statistical Abstract of the Unites States, 1993 (p. 402) were used to obtain updated proportions of women and men in the workforce, which were then used to assess the weighted average of 
the workforce mix. Manning, et al.'s assumption that 38 percent of the work loss is covered by sick leave was left unchanged. Group Life Insurance

Group coverage per worker is estimated by Manning, et al. (1991) to be $\$ 19,300$, which in 1992 dollars is $\$ 24,195$. In 1992 there were 117.598 million workers, and total group life insurance coverage in the United States was estimated to be $\$ 4,240,919$ (American Council of Life Insurance in World Almanac and Book of Facts, 1994).

\section{Nursing Home Care}

Manning states that 4.79 percent of the population over 65 is in nursing homes and that $\$ 9,247$ ( $\$ 12,191$ in 1993 dollars) is the annual covered cost per patient. In 1990, 5.09 percent of the population over 65 was in nursing homes (U.S. Department of Commerce, Statistical Abstract of the United States, 1993 and Wor ld Almanac and Book of Facts, 1994). In addition to adjusting for the changing nursing home population, there is also an adjustment for the cost of nursing home care. In 1990 the covered cost per patient was $\$ 21,290$ (amount in 1993 dollars following the same procedure as above).

\section{Retirement Pensions}

In estimating the costs of pensions, Manning, et al. (1991) included Social security, supplemental security Income (SSI), public assistance, veteran's compensation, and pension income (using 1985 data). To address trends in these amounts, estimates were obtained from the U.S. Department of Labor, Trends in 
Pensions, 1992 and U.S. Department of Health and Human Services, Annual statistical supplement of the social security Bulletin.

1993. The updated figures are for 1992 .

Trends in the proportion of the population covered by these programs were also taken into account. A weighted average (weights based on gross outlays of these programs) of the percentage change of those over 65 receiving payments was used to derive the adjustment factor. To calculate the cost adjustment factor, the weighted real increase in the value of payments made to recipients was used.

\section{Fires}

Manning, et al. (1991) estimate that fires caused by smokers lead to $\$ 405.14$ million in damages (1990 dollars converted from 1986 dollars). According to FEMA (Fire in the United States: 1983-1990, National Fire Data Center, FEMA, 1993). In 1990, there were $\$ 354.5 \mathrm{million}$ in damages attributable to smokers. Taxes on Earnings

Manning, et al. used the 1985 CPS to determine earnings received. This figure was updated using information from the employment cost index, which appears in the U.S. Department of Commerce, Statistical Abstract of the United States, 1993.

Taxes on earnings were calculated as being the amount that an individual would pay toward the above costs. It was calculated in such a way that taxes collected equal costs. Since Manning, et al.'s (1991) analysis, total costs have risen by 40 percent. However, the demographics of smoking have changed so 
that the non-smoking smoker is now of a lower socioeconomic class than in 1975 and, thus, is subsidized by society to a greater extent than before. This would tend to proportionally shrink taxes on earnings for both smokers and non-smoking smokers. per Capita Cigarette consumption

The cost estimates have been adjusted for changes in the per capita consumption of cigarettes. Data for 1923 to $1990 \mathrm{cn}$ per capita cigarette consumption is drawn from the National Cancer Institute, U.S. Department of Health and Human Services, Strategies to control Tobacco Use in the United States. Data for 1991 to 1993 are drawn from the U.S. Department of Agricuiture, Tobacco Situation and outlook Report, September 1993.

Percentage of Population Smoking (P)

Data ( smoking $\geq 20$ years of age) for $1965-66,70,74,76-$ 80,83 , and 85 from Reducing the Health Consequences of Smoking: 25 Years of Progress, a Report of the Surgeon General, U.S. Department of Health and Human Services, 1989, p. 269. Data (8 smoking $\geq 18$ years of age) for $1987-88$ and 90 from Health United States, 1991, U.S. Department of Health and Human Services, 1992, p. 203. Data $(\geq 18)$ for $1949,57,58$ and 64 from smoking and Health, a Report of the Surgeon General, U.S. Department of Health and Human Services, 1979, p.A-9. Data ( $\geq 18)$ for 1995, 91 from Center for Disease Control via "Smoking Split Decision" The Courier Journal, 1/9/94, pl. All other years are linearly estimated using the two closest years from which data is available. 
$\underline{\operatorname{Tar}(T)}$

Data for 1954, and 68-83 is from Smoking, Tobacco, and health: A Fact Book, CDC, DHHS, p.21. Data for 1955-67 is from The Health Consequences of Smoking: The Changing Cigarette, A Report of the Surgeon General, DHHS, 1981, p.207. Data for 1984 to 1993 is derived by running a regression of $z<15 \mathrm{mg}$ on tar for 1967 to 1983 and using the resulting coefficient to estimate tar levels. Data for 1923 to 1954 is derived by running a regression of year on tar and using the resulting coefficient to estimate tar levels.

Less than $15 \mathrm{mg}$

Data is taken from Federal Trade Commission Report to Congress for 1990: Pursuant to the Federal Cigarette Labeling and Advertising Act, 1992, FTC, 1992, pp.28-30.

Unadjusted Packs per Smoker (S)

$$
S=(C / 20) /(P / 100)
$$

Tar-adjusted Per Capita cigarette Consumption (CA)

$$
C A=C \star T / 46.1
$$

Tar-adjusted Packs per Smoker (SA)

$$
S A=(C A / 20) /(P / 100)
$$

Tar Adjustment (TAR)

The example below is for the twenty year moving average case. The value of cons is also for this case.

$$
T A R=\operatorname{SUM}\left(T_{y-20}, T_{y-1}\right) / \operatorname{SUM}\left(T_{1994}, T_{2013}\right) \text {. }
$$

Consumption Adjustment (CONS):

$$
\text { CONS }=\operatorname{SUM}\left(S_{y-20} . S_{y-1}\right) / \operatorname{SUM}\left(S_{1994}, T_{2013}\right) .
$$




\section{Discount Rates}

The Manning $0 \%$ and $5 \%$ rates were taken from the Manning study. The Manning $3 \%$ rate was calculated in the following manner. First, Table A was constructed using data from Appendix G and pp. 36-37 (in Manning). this gives the absolute and proportional values for medical costs. From this it was found that a $3 \%$ discount rate is equivalent to the 58 number plus $168-$ $20 \%$ of the difference between $0 \%$ and $5 \%$ (depending upon whither the cost in question occurs relatively early or late in life). The lack of data for nonmedical costs resulted in educated guesses being made in this range. 


\section{References}

Ames, Bruce N. and Lois S. Gold (1993), "Environmental Pollution and Cancer: Some Misconceptions," in Kenneth R. Foster, David E. Bernstein, and Peter w. Huber, Phantom Risk, Cambridge: MIT Press, pp. 153-181.

Becker, G.S. (1991), A Treatise on the Family, Cambridge: Harvard University Press.

Becker, G.S., M. Grossman, and K.M. Murphy (1988), "A Theory of Rational Addiction," Journal of Political Economy 96: 675700 .

Becker, G.S., M. Grossman, and K.M. Murphy (1990), "An Empirical Analysis of Cigarette Addiction," NBER Working Paper No. 3222. Cambridge, MA: National Bureau of Economic Research. (June 1994), "An Empirical Analysis of Cigarette Addiction," American Economic Review. Beyth-Marom, R., L. Austin, B. Fischhoff, Palmgren, and M. Jacobs-Quadrel (1993), "Perceived Consequences of Risky Behaviors: Adults and Adolescents," Developmental Psychology $29(3): 549-63$.

Calfee, J.E. (1986), "Cigarette Advertising, Health Information and Regulation," FTC Working Paper.

Canadian Department of National Health Welfare (1993), HealthRisk Perception in Canada, Ottawa: Minister of Supply and Services Canada.

Center for Disease Control, U.S. Department of Health and Human Services (1989), Smoking, Tobacco and Health: A Fact Book. (August 27, 1993), "Cigarette Smoking - 
Attributable Mortality and Years of Potential Life Lost United States, 1990," Morbidity and Mortality Weekly Report $42(33): 645-649$. (May 20, 1994), Morbidity and Mortality

Weekly Report, p. 342. Cothern, C. Richard (1992), Comparative Environmental Risk Assessment, Boca Raton: Lewis Publishers. Federal Emergency Management Agency (1993), Fire in the U.S. Washington: U.S. Government Printing office. Federal Register (April 5, 1994), pp. 15968-16039. Federal Trade Commission (1992), Federal Trade Commission Report to Congress for 1990: Pursuant to the Federal Cigarette Labeling and Advertising Act, 1992. Fullerton, Don and D.L. Rodgers (1993), Who Bears the Lifetime Tax Burden? Washington: Bookings Institution. Gravelle, J. and D. Zimmerman (1994), Cigarette Taxes to Fund Health Care Reform: An Economic Analysis," Washington, DC: Congressional Research Report.

Grossman, M. (1991), "The Demand For clgarettes," Journal of Health Economics, $10(1): 101-03$. Harris, J.E. (1980), "Taxing Tar and Nicotine," American Economic Review 70: 300-11.

Hersch, Joni and w. Kip Viscusi (1990), "Cigarette Smoking, Seatbelt Use, and Differences in Wage-RIsk Trade-offs," Journal of Human Resources 25(2): 202-227. International Agency for Research on Cancer (1985), Tobacco: A Major International Health Hazard, New York: Oxford 
University Press.

Ippolito, P.M. (1987), "The Value of Life Saving: Lessons from the Cigarette Market," Risk Assessment and Management, ed.

L.B. Lave, New York: Plenum Press.

Ippolito, P.M. and R.A. Ippolito (1984), "Measuring the Value of

Life Saving from Consumer Reactions to New Information,"

Journal of Public Economics 25: 53-81.

Jacobs-Quadrel, M., B. Fischhoff, and W. Davis (1993),

"Adolescent (In) vulnerability," American Psychologist 48(2): 102-116.

Janerich, D.T., et al. (1990), "Lung Cancer and Exposure to

Tobacco Smoke in the Household," The New England Journat of

Medicine 323: 632-636.

Manning, W.G., E.B. Keeler, J.P. Newhouse, E.M. Sloss, and J.

Wasserman (1989), "The Taxes of Sin: Do Smokers and Drinkers

Pay Their Way?" Journal of the American Medical Association

261(11): 1604-1609.

(1991), The costs of Poor Health Habits.

Cambridge: Harvard University Press.

Mulholland, J. (1991), "Policy Issues Concerning the Promotion of

Less Hazardous Cigarettes," Bureau of Economics, Federal

Trade Commission, Working Paper.

Poterba, J.M. (1989), "Lifetime Incidence and the Distributional

Burden of Excise Taxes," American Economic Review 79(2):

$325-330$.

Schelling, T.C. (1984), Choice and Consequence. Cambridge:

Harvard University Press. 
Schneider, F.W., and L.A. Vanmastrig (1974), "Adolescent Preadolescent Differences in Beliefs and Attitudes About Cigarette Industry," Southern Economic Journal 38(3): 325335 .

Shoven, J.B., J.O. Sundberg, and J.P. Bunker (1987), "The Social Security cost of Smoking." National Bureau of Economic Research Working Paper no. 2234.

Steenland, Kyle (1992), "Passive Smoking and the Risk of Heart Disease," Journal of the American Medical Association $267(1): 94-99$.

Tobacco Institute (1993), The Tax Burden on Tobacco: Historical Compilation 1993. Vol. 28. Washington, D.C.: Tobacco Institute.

U.S. Bureau of Alcohol, Tobacco, and Firearms (1988), "Final Report of the Research Study of Public opinion Concerning Warning Labels on Containers of Alcoholic Beverages, Vol. 1.

U.S. Department of Health, Education, and Welfare (1964), Smoking and Health: Report of the Advisory committee to the Surgeon General of the Public Health Service, Princeton: Van Nostrand.

U.S. Department of Health, Education, and Welfare (1968), Supplement to the 1967 Public Health Service Review. Washington, D.C.: U.S. Government Printing office.

U.S. Department of Health and Human Services (1981), The Health Consequences of Smoking: The Changing cigarette, A Report of the Surgeon General. 
U.S. Department of Health and Human Services (1988), The Health Consequences of Smoking: Nicotine Addiction, A Report of the Surgeon General, Washington: U.S. Government Printing office.

U.S. Department of Health and Human Services (1989), Beducing the Health Consequences of Smoking: 25 Years of Progress, washington, D.C.: U.S. Government Printing office.

U.S. Environmental Protection Agency (1994), The costs and Benefits of Smoking Restrictions: An Assessment of the Smoke-Free Environment Act of 1993 (H,R.3434) Indoor Air Division, office of Radiation and Indoor Air Washington: U.S. Environmental Protection Agency. Viscusi, W.K. (1990), "Do Smokers Underestimate Risks?" Journal of Political Economy 98(6): 1253-1269. (1991), "Age Variations in Risk Perceptions and Smoking Decisions," Review of Economics and Statistics 73: $577-588$. (1992a), Fatal Tradeoffs: Public and Private Responsibilities for Risk, New York: oxford University Press. (1992b), Smoking: Making the Risky Decision. New York: Oxford University Press. (1993), "The Value of Risks to Life and Health," Journal of Economic Literature XXXI(4): $1912-1946$. (1994), "Cigarette Warnings: The Perils of the Cipollone Decision," Supreme Court Economic Review 3: 239275 . 
Wasserman, J., W.G. Manning, J.P. Newhouse, and J.D. Winkler (1991), "The Effects of Excise Taxes and Regulations on Cigarette Smoking," Journal of Health Economics 10(1): 4364. 